\title{
LA IMPORTANCIA DE LA PROTECCIÓN DE LOS DERECHOS DE PROPIEDAD EN EL SISTEMA FINANCIERO Y EN EL CRECIMIENTO ECONÓMICO
}

\author{
Lorenza Martínez Trigueros* \\ Diciembre de 2000 \\ Documento de Investigación No. 2000-07 \\ Dirección General de Investigación Económica \\ BANCO DE MÉXICO
}

\footnotetext{
* La autora pertenece a la Dirección de Estudios Económicos del Banco de México. Agradezco los comentarios de Guillermo Babatz, Armando Baqueiro, Sara Gabriela Castellanos, Rafael del Villar, Miguel Messmacher, Mario Tamez, Héctor Tinoco, Alejandro Werner y de los participantes del Seminario de la Dirección de Estudios Económicos del Banco de México, así como la ayuda de Gabriel Cuadra y Judith Frías en la elaboración de este documento. Las opiniones contenidas en este documento corresponden exclusivamente al autor y no representan el punto de vista del Banco de México.
} 


\title{
LA IMPORTANCIA DE LA PROTECCIÓN DE LOS DERECHOS DE PROPIEDAD EN EL SISTEMA FINANCIERO Y EN EL CRECIMIENTO ECONÓMICO
}

\author{
Lorenza Martínez Trigueros \\ lmartin@banxico.org.mx
}

Diciembre del 2000

Documento de Investigación No. 2000-07

\begin{abstract}
Resumen
El objetivo de este trabajo es el de estudiar la importancia e influencia de algunos instrumentos a disposición del gobierno para proteger los derechos de propiedad de acreedores garantizados y accionistas minoritarios sobre el desarrollo de los mercados financieros y, en última instancia, sobre el crecimiento económico. Con este fin se realiza un análisis econométrico de corte transversal con una muestra de 47 países para el período 1976-93. Los resultados más relevantes indican que una regulación adecuada en materia de protección a acreedores y accionistas minoritarios contribuye significativamente al desarrollo del sistema financiero. La realización de reformas legales en estos ámbitos en México podría aumentar la tasa de crecimiento económico entre 0.8 y 1.6 puntos porcentuales.
\end{abstract}




\section{Introducción}

El papel que tienen los servicios financieros en el desarrollo económico resulta de importancia fundamental. Al realizar sus operaciones, los intermediarios financieros proveen servicios tales como movilización del ahorro, evaluación de proyectos, manejo de riesgos, vigilancia de los administradores y facilidades para ejecutar transacciones (Schumpeter, 1911) ${ }^{1}$. En consecuencia, dichos intermediarios son esenciales para la innovación tecnológica y para el desarrollo económico.

Esta visión de la banca y, en general, del sistema financiero es comúnmente aceptada. Sin embargo, no existe un consenso acerca de la magnitud de su contribución. Por ello, es preciso aislar esta variable de otras que también contribuyen significativamente al crecimiento económico y que, generalmente, están altamente relacionadas con el desarrollo del sistema financiero. Por otro lado, poco se ha dicho en cuanto a medidas concretas que contribuyan al desarrollo de estos sectores.

Profundizar en el estudio de propuestas encaminadas a promover el desarrollo y la eficiencia de la intermediación financiera en México es crucial. México se encuentra rezagado en este sector no sólo a nivel internacional sino incluso comparado con países latinoamericanos. En términos del mercado de valores, México alcanzó un nivel de capitalización de mercado de $24 \%$ del PIB durante 1998, mientras que el promedio internacional se encontraba cerca de $35 \%$. Por lo que respecta al desarrollo del sistema bancario, mucho se ha dicho de los problemas que ha enfrentado recientemente, pero aun en 1994, cuando alcanzó un máximo histórico, sólo llegó a representar 24\% del PIB, mientras que el promedio para los países latinoamericanos era entonces de $34 \%$.

El objetivo de esta investigación es el de estudiar la importancia e influencia de algunos instrumentos a disposición del gobierno para proteger los derechos de propiedad de acreedores garantizados y accionistas minoritarios sobre el desarrollo de los mercados financieros y, en última instancia, sobre el crecimiento económico. Adicionalmente, la calidad del sistema de impartición de justicia resulta un determinante importante en este

\footnotetext{
${ }^{1}$ Nota tomada de King y Levine (1993).
} 
ámbito, por lo que también se considera en el análisis empírico. Sin embargo, por su complejidad no se enfatizan los efectos de esta variable en la instrumentación de políticas enfocadas a ese objetivo, salvo en el caso de su incidencia sobre los flujos de capitales internacionales.

La relevancia del trabajo, además de identificar aspectos específicos de regulación o intervención del gobierno que pueden promover el desarrollo del sistema financiero y así fomentar el crecimiento económico del país, consiste en utilizar una metodología innovadora para cuantificar la magnitud de este efecto.

Con este objetivo, primero se estimó el impacto que tienen ciertas disposiciones legales encaminadas a proteger los derechos de acreedores garantizados y de accionistas minoritarios sobre el desarrollo de los mercados financieros. Posteriormente, se calculó el efecto que tiene el desarrollo de los mercados financieros sobre el crecimiento económico. Para este propósito es importante tomar en cuenta la existencia de un problema de endogeneidad, el cual consiste en que así como el crecimiento se ve favorecido por un sistema de intermediación eficiente, este último mejora cuando se tiene un mayor crecimiento económico. Lo anterior implica que al realizarse una regresión de mínimos cuadrados ordinarios se captan ambos efectos, sin poder distinguirse cada uno de ellos por separado. Para resolver este problema se utiliza el método de mínimos cuadrados en dos etapas, tomando las características del sistema legal como instrumentos del desarrollo del sistema financiero. Esta metodología resuelve el problema de endogeneidad, ya que tal como lo expresan La Porta, López de Silanes, Shleifer y Vishny (LLSV 1998), las variables de la legalidad dependen primordialmente de la familia de la que proviene el sistema legal y, por tanto, son independientes del nivel de desarrollo del país.

El análisis econométrico es de corte transversal con una muestra de 47 países para los cuales se utiliza el promedio de las variables durante el período 1976-93, usando una observación por país. Los resultados más relevantes indican que una regulación adecuada en materia de protección a acreedores y accionistas minoritarios contribuye significativamente al desarrollo del sistema financiero. De incluirse las medidas aquí propuestas en la reglamentación del mercado de valores de México, el valor de capitalización de éste en términos del PIB podría duplicarse. En términos del mercado 
crediticio los resultados indican que la Ley de Concursos Mercantiles (LCM) y la Miscelánea de Garantías al Crédito podrían redundar en un incremento promedio en el crédito bancario al sector privado de entre $7 \%$ y $14 \%$ del PIB.

Con la realización de las reformas legales propuestas en este estudio, para la protección de acreedores garantizados y de accionistas minoritarios, la tasa anual de crecimiento de la economía mexicana podría incrementarse entre 0.8 y 1.6 puntos porcentuales.

El resto del artículo se organiza de la siguiente manera. La sección II describe la importancia de un marco regulatorio que proteja de manera adecuada los derechos de propiedad para el desarrollo de los mercados financieros y el papel que juegan éstos como motor del crecimiento económico. En la sección III se presenta el análisis empírico y la descripción de los datos utilizados. Una revisión del entorno legal en México, enfatizando la regulación en cuanto a la protección de derechos a accionistas minoritarios se incluye en la sección IV. Finalmente en la sección V se ofrecen algunas conclusiones.

\section{El Entorno Legal, el Desarrollo de los Mercados Financieros y el Crecimiento Económico}

El funcionamiento eficiente de los mercados financieros, constituidos por el crediticio y el accionario, requiere de un entorno legal adecuado que solucione los problemas de agencia ${ }^{2}$ que resultan bajo condiciones de libre mercado.

En el mercado accionario el problema de agencia se debe a que en las empresas que cotizan en bolsa se separan la propiedad y el control de la empresa. Babatz (1997) explica cómo este problema se deriva del conflicto de intereses que surge de esta separación:

\footnotetext{
${ }^{2}$ Los problemas de agencia surgen de un contrato en el que el "beneficio" que recibe una de las partes, denominada principal, depende del comportamiento de la otra parte, denominada agente. El problema surge debido a que los intereses de las partes difieren y a que el principal desconoce cierta información en relación al agente. Ambos factores conducen a una situación en la que el agente tiene el incentivo a ver por sus intereses en perjuicio del beneficio del principal.
} 
Los grandes accionistas representan a sus propios intereses, que no necesariamente coinciden con los intereses de otros inversionistas en la empresa. Al utilizar sus derechos de control para maximizar su propio bienestar, los grandes accionistas pueden apropiarse de los recursos de otros - tanto de forma eficiente como ineficiente. Si este problema de agencia entre inversionistas mayoritarios y otros inversionistas no puede resolverse a través de regulación, entonces el financiamiento externo será escaso (LLSV, 1997) e inversiones potencialmente productivas no serán realizadas.

En este caso los inversionistas potenciales no tendrán incentivos a participar como accionistas minoritarios o bien exigirán un premio por el riesgo a ser expropiados por los grandes accionistas. En consecuencia, los dueños de empresas que busquen financiamiento para proyectos rentables encontrarán que la obtención de éste vía emisión de capital resulta muy cara en el mejor de los casos e inaccesible para la mayoría de empresas.

La evidencia en cuanto a los mecanismos que utilizan los dueños que ejercen el control para expropiar $^{3}$ a los minoritarios es escasa. Para el caso de los E.U.A., los resultados encontrados en la literatura son mixtos. Por un lado, Barclay y Holderness (1989) encuentran cierta evidencia de expropiación, mientras que Malitz (1989) y Slovin y Sushka (1997) no encuentran evidencia de expropiación a pequeños accionistas en empresas emisoras de este país. Shleifer y Vishny (1997) reportan casos en los que los chaebols coreanos vendieron sus subsidiarias a parientes de los fundadores de los chaebols a precios inferiores a los de mercado. Claessens et al (1999) presentan evidencia, usando empresas asiáticas, del efecto de separar el control de la propiedad, sobre los incentivos para expropiar a las minorías.

Para México y Chile existe evidencia anecdótica y periodística de casos de expropiación a accionistas minoritarios. También Babatz (1997) presenta otros casos en los que los dueños

\footnotetext{
3 A lo largo del documento se entiende por expropiar, a las acciones realizadas por los accionistas mayoritarios de una empresa en beneficio propio a costa del valor de la empresa, implicando el despojo de parte del patrimonio de los accionistas minoritarios.
} 
mayoritarios que también fungen como directivos, han llevado a cabo acciones en su propio beneficio y en contra de los intereses de la empresa.

La legislación que rige las prácticas de gobierno corporativo tiene el propósito de resolver estos problemas de información asimétrica, asegurando un grado de protección mínima de los intereses de inversionistas externos. Otra alternativa para la solución del problema de agencia, que surge cuando los mecanismos de gobierno corporativo no son eficientes debido a mala legislación, a la ineficiencia del sistema judicial o a ambas- es la concentración de la propiedad. Mientras que la concentración de la propiedad no requiere un papel muy activo de los tribunales, sí logra alinear los incentivos para la maximización de beneficios en la empresa. Babatz (1997) analiza este aspecto para México y encuentra que en efecto la concentración tiende a ser mayor que en países que cuentan con una mejor protección de las minorías. Sin embargo, esto no soluciona el problema de subinversión y mientras la concentración no sea total no se resuelve completamente el problema de agencia. Este argumento es presentado en Shleifer y Vishny (1997) y corroborado con evidencia internacional al comparar la estructura legal y la concentración de propiedad de empresas que cotizan en bolsa en distintas economías (LLSV, 1998).

La importancia de la calidad de la legislación en el desarrollo de prácticas corporativas sanas es patente al observarse que, si bien en casi todos los países ocurren casos de expropiación a minorías, éstos son más frecuentes en aquellos países que cuentan con una regulación deficiente, tales como Italia, México, Corea, Indonesia y Tailandia, entre otros. Los datos y las comparaciones de las legislaciones corporativas se presentan en la sección relativa al análisis empírico.

Gibson (1999) realiza un estudio, utilizando datos de economías emergentes, sobre la relación entre un mal desempeño en cuanto a ganancias de una empresa y el cambio de administración. Con esto busca probar si la creencia de que el gobierno corporativo en economías emergentes es sumamente ineficiente tiene fundamento. Con este propósito divide a los países de acuerdo a la tradición del sistema legal en civil y común, la cual de acuerdo a LLSV (1997) resulta ser el determinante más importante en cuanto a la protección de los derechos de los accionistas minoritarios. Sus resultados indican que no es claro que en los países con tradición civil, la cual conlleva una pobre protección de este tipo 
de derechos, el cambio de administración sea menos frecuente después de un mal desempeño. Este resultado implica que aún con una mala regulación se pueden alinear los incentivos mediante otros mecanismos de manera que se lleven a cabo las acciones óptimas para las empresas. Sin embargo, como sucede cuando se da la concentración de la propiedad, esto no necesariamente implica que se resuelva el problema de subinversión. Además, es importante mencionar que dichos resultados pueden ser cuestionados ya que la muestra de países es muy pequeña y no es representativa de los países con sistemas legales de tradición civil. Al observar con mayor cuidado la muestra de países, se detectó que dentro de los que cuentan con una tradición de sistema legal civil se incluye a México, Corea, Taiwan, Brasil y Chile. Estos países en general cuentan con una protección de derechos mucho más estricta que el resto de los países con sistemas legales provenientes de la misma tradición. La protección que brinda a los accionistas minoritarios la regulación chilena alcanza el máximo nivel mundial, mientras que las de Taiwan y Brasil están en un nivel medio, incluso mejor que Tailandia, la cual está dentro de su muestra de países con tradición común. Por ende, no es claro que los resultados se mantendrían si se clasificaran los países de acuerdo a las medidas legales consideradas en su regulación o alternativamente se incluyeran más países en el análisis.

Otro tipo de comportamiento similar, por el que los inversionistas externos se ven perjudicados, es el del uso de información privilegiada. Bhattacharya, U. et al (2000) encuentran evidencia que sustenta la teoría de que el mercado de valores mexicano se caracteriza por el uso de información privilegiada, lo que ocasiona que las noticias de empresas emisoras no afecten el precio de sus acciones. Esto indica que a pesar de que la Ley del Mercado de Valores prohibe el uso de información privilegiada, no se ha logrado abatir este tipo de conducta. Dichos autores encuentran que este comportamiento se refleja en el hecho de que antes de que se anuncien públicamente las noticias, la volatilidad del rendimiento de las emisiones de series-A (sólo pueden ser operadas por nacionales) siempre lleva a volatilidad en el rendimiento de las series-B (pueden pertenecer a extranjeros). Lo anterior sugiere que la información fluye de las series-A hacia las seires-B. Lo anterior ejemplifica la importancia de contar con instituciones de procuración de justicia que se encarguen de que las leyes se cumplan. 
En el mercado crediticio ocurre un problema de riesgo moral afín. Este se da porque las pérdidas del deudor en caso de que fracase el proyecto o de que no pague su deuda están limitadas a cero, siempre que no se tenga una garantía sobre el crédito, mientras que sus ganancias no tienen un límite similar. Como es sabido, el resultado es que dicho agente tiene incentivos a llevar a cabo proyectos demasiado riesgosos. Existen al menos dos opciones para solucionar este problema: la exigencia de un colateral para garantizar el crédito o bien utilizar el historial crediticio para el otorgamiento de nuevos créditos. Ambas alternativas logran aumentar el costo de no pago para el deudor. Un proceso de quiebra llevado a cabo de manera eficiente resulta ser un caso especial de la ejecución del colateral.

En ausencia de mecanismos legales adecuados resulta muy difícil para los acreedores hacer valer sus garantías, encareciéndose el crédito y desincentivándose el desarrollo de los mercados crediticios. En cambio, una regulación enfocada a facilitar la recuperación del colateral llevará al resultado opuesto.

La literatura en este ámbito es igualmente extensa. LLSV (1997) y Levine (1998) analizan el impacto que tiene una regulación que protege a los acreedores garantizados sobre el desarrollo del mercado crediticio, entendiéndose este último como el tamaño del sector en términos del monto de créditos vigentes. Por otro lado, se tienen estudios que analizan como afectan las leyes de quiebras al desempeño de los administradores y en última instancia al acceso de las empresas al crédito (Berkowitz y White (1999), Pulvino (1999), Thorburn (1999), Thorburn (1998) y White (1996)).

Así, la primera hipótesis del trabajo plantea que entre mejor sea la regulación con respecto a la protección de los inversionistas y de los acreedores, más desarrollados serán los mercados de valores y crediticios. Para el análisis empírico se consideran las normas que se han utilizado en la práctica para proteger a inversionistas y acreedores, así como algunos indicadores que miden la calidad del sistema de impartición de justicia.

Una regulación encaminada a proteger a los accionistas minoritarios y a los acreedores garantizados ayudará a resolver los problemas de información asimétrica patentes en los mercados financieros. Sin embargo, cabe destacar que la calidad de las instituciones legales y, en general, la del sistema de impartición de justicia juegan un papel fundamental en el desarrollo del sistema financiero y que el no controlar por estos factores en el análisis 
empírico podría llevar a una mala interpretación de los resultados obtenidos. Si el sistema de impartición de justicia es el factor más importante en la determinación del desarrollo del sistema financiero y a su vez está correlacionado con la protección de acreedores o de accionistas minoritarios, al no controlar por aquél se tendría un problema de correlación espuria, esto es, se podría concluir erróneamente que la protección de derechos es determinante en el desarrollo del sistema financiero. Una preocupación adicional en cuanto a la interrelación de la regulación y el sistema de justicia es la siguiente: ¿Tiene una regulación adecuada efectos positivos aun cuando no se cuente con las instituciones adecuadas que la haga valer?. Por esto es importante llevar a cabo estimaciones en las que el efecto de la protección de derechos dependa de la calidad del sistema judicial.

Otros autores han investigado hipótesis similares a la aquí propuesta. Por ejemplo, LLSV (1997) toman una muestra de 49 países para analizar si la protección a los derechos de los inversionistas implica mercados financieros más desarrollados. Estos autores encuentran que los factores que miden dichos derechos tienen un efecto significativo y que las medidas relativas a los derechos de accionistas minoritarios son más efectivas que las de derechos de acreedores. Es importante resaltar que también incluyen variables del origen del sistema legal y que éstas son significativas. Esto es, las medidas incluidas no son suficientes para captar la totalidad del impacto de la regulación, por lo que deben existir otros aspectos regulatorios importantes que crean un ámbito adecuado para el desarrollo de los mercados financieros. La contribución del presente trabajo consiste en analizar si los resultados propuestos por estos autores son robustos a diferentes especificaciones, así como determinar cuáles son las medidas regulatorias más importantes por su contribución al desarrollo de los mercados financieros. A su vez, dichas medidas se utilizan para evaluar la segunda hipótesis.

La segunda hipótesis de este trabajo plantea que el desarrollo de los mercados financieros tiene un efecto positivo sobre el crecimiento económico. Esta hipótesis no es nueva en la literatura. Existen diversos trabajos que han investigado la importancia del desarrollo de los mercados financieros en la determinación de la inversión y del crecimiento económico. Rajan y Zingales (1996) consideran que el desarrollo financiero debería facilitar el crecimiento debido a que reduce los costos del financiamiento externo de las empresas. Para probar su hipótesis utilizan un análisis microeconómico comparando los sectores 
industriales entre países, con el propósito de encontrar si aquellos sectores que requieren mayor financiamiento externo se expanden más en países donde los mercados financieros están más desarrollados. Sus resultados indican que en efecto se cumple su hipótesis para una muestra de países durante los ochenta.

King y Levine (1993) también analizan el efecto del desarrollo del sistema financiero en el crecimiento económico para una muestra de 80 países para el período de 1960 a 1989. Para medir el desarrollo financiero, consideran indicadores como la penetración del sistema financiero, definida como la razón de los pasivos líquidos a PIB, los depósitos bancarios en relación al crédito interno otorgado por el banco central, el crédito al sector privado nofinanciero como proporción del crédito total y del PIB. Encuentran que todos los indicadores tienen una correlación positiva y significativa con las variables de crecimiento utilizadas. Para resolver el problema de endogeneidad, realizan estimaciones tomando los valores iniciales del desarrollo del sistema financiero como variables explicativas del crecimiento futuro. También en este caso encuentran un efecto positivo y significativo.

Levine y Zervos (1998) usando información para 47 países de 1976 a 1993, analizan si el desarrollo de los mercados de valores y bancario promueve el crecimiento de largo plazo. Encuentran que la liquidez del mercado de capitales y el desarrollo del sistema bancario predicen mayores tasas de crecimiento, acumulación de capital y productividad. También concluyen que el tamaño del mercado de valores, su volatilidad y la integración internacional no tienen efectos significativos en la tasa de crecimiento de las variables mencionadas. Estos autores mencionan que desde el punto de vista teórico el efecto de la integración internacional de capitales en el crecimiento es ambiguo. Por un lado, aumenta la productividad al mover recursos de inversiones seguras poco rentables a las más rentables. Mientras que, por otro lado, puede reducir el ahorro al hacer más accesible el endeudamiento, disminuyendo también la inversión y en última instancia el crecimiento económico. También el aumento de liquidez puede ocasionar que, al ser más fácil vender las acciones, se pueda reducir el incentivo de los accionistas a llevar a cabo la vigilancia sobre los administradores, ocasionando una caída en la productividad.

La metodología presentada en este artículo es muy similar a la desarrollada por Levine, Loayza y Beck (1998), quienes también utilizan las medidas regulatorias de protección de 
derechos como instrumentos para estimar el efecto del mercado crediticio sobre el crecimiento económico. La aportación del presente trabajo radica en que también se considera al mercado accionario, se incluyen especificaciones adicionales para corroborar que los resultados sean robustos, además de que se analiza el papel que juega el flujo de capitales externos en este ámbito.

\section{Análisis Empírico}

En esta sección se presentan los resultados principales de un estudio econométrico realizado con base en la experiencia de 40 países, durante el período de 1976 a 1993, con relación a:

- El impacto de la legalidad en el mercado crediticio.

- El impacto de la legalidad en el mercado de valores.

- El efecto del desarrollo de los mercados financieros sobre el crecimiento económico.

\subsection{Descripción de variables y sus fuentes}

Para este propósito primero se describen las variables utilizadas en cuanto a lo siguiente:

- Medición del cumplimiento de la legalidad.- Los índices que se utilizaron son calculados por distintas agencias, tales como International Country Risk y Business International Corporation.

- Medición de la protección a acreedores.- Las variables utilizadas para este propósito vienen de LLSV (1998), quienes consideran la regulación de cada uno de los países estudiados en cuanto a la inclusión de cinco aspectos específicos para proteger a los acreedores garantizados.

- Medición de la protección a accionistas minoritarios.- Estas variables también provienen de LLSV (1998), quienes en este caso consideran nueve aspectos regulatorios.

- Variables del desarrollo del sistema financiero 
- Variables usadas como controles

- Otras variables.

Se consideraron siete variables diferentes para la medición del cumplimiento de la legalidad. El propósito es utilizar dichas variables como indicadores del nivel de desarrollo o de la eficiencia que muestran las instituciones encargadas de hacer valer las leyes.

1. Eficiencia del sistema judicial (E.S.J): Indice de la eficiencia e integridad del ambiente legal en cuanto a la protección de empresas, en particular con respecto al trato que reciben las empresas extranjeras. Promedio de 1980 a 1983. Escala de 0 a 1, siendo 1 el máximo nivel de eficiencia. Fuente: Business International Corporation.

2. Riesgo de expropiación (Exprop): Calificación del riesgo de nacionalización. Promedio de los meses de abril a octubre de 1982 a 1995. Escala de 0 a 1, siendo 0 el nivel de mayor riesgo. Fuente: International Country Risk.

3. Riesgo de que el gobierno repudie los contratos establecidos (Contratos): Calificación del riesgo de que el gobierno modifique, repudie o posponga un contrato debido a recortes presupuestales, presión política, cambio de gobierno u otras causas. Promedio de los meses de abril y octubre de 1982 a 1995 . Escala de 0 a 1, donde las calificaciones más bajas corresponden a mayores riesgos. Fuente: International Country Risk.

4. Nivel de corrupción del país (Corrup): Calificación de la corrupción en el gobierno. Calificaciones más bajas indican que altos funcionarios públicos probablemente demandan pagos especiales y que pagos ilegales son generalmente esperados en los niveles más bajos del gobierno, en forma de sobornos relacionados con licencias de exportación e importación, controles de cambios, impuestos, políticas de protección o préstamos. Escala de 0 a 1 , donde 0 es el máximo nivel de corrupción. Fuente: International Country Risk.

5. Protección de derechos de propiedad (Der-prop): Indice de protección de la propiedad privada. La calificación se basa en el grado de protección legal a la propiedad privada, la probabilidad de que el gobierno la expropie y el grado en que el gobierno hace cumplir las leyes que la protegen. Escala de 0 a 1 , donde 1 es el máximo nivel de protección. Fuente: Index of Economic Freedom - Country Ranking, 1997. 
6. Cumplimiento de la legalidad (Seg-Leg): Calificación de la tradición de legalidad y orden del país. Escala de 0 a 1, siendo 1 el máximo nivel de respeto de la legalidad. Fuente: International Country Risk.

A pesar de ser muy similares, estas variables podrían capturar diferentes aspectos tales como el nivel de corrupción y el riesgo de expropiación. Sin embargo, al comparar las correlaciones entre estas variables en el Cuadro 1 se aprecia que son muy altas y significativas, de modo que en el análisis econométrico sería muy difícil distinguir entre el efecto de cada una de ellas. Por otro lado, tampoco está en el interés de este documento abundar sobre la importancia que tiene un sistema de impartición de justicia eficiente, debido a que esta idea ya ha sido ampliamente estudiada (Gupta et al, 1998; Knack et al, 1996; Mauro, 1995) y, como se mencionaba anteriormente, por la dificultad de proponer medidas para mejorar la calidad de éste. Por esta razón, sólo se incluye una de estas variables como control, tomando en cuenta que capturará gran parte de los efectos del resto de las variables. La inclusión de este tipo de variables es de suma importancia para evaluar hasta qué grado puede avanzarse en el desarrollo de los mercados financieros mediante reformas en la regulación cuando no se tienen instituciones que efectivamente hagan valer las leyes. Únicamente se considera el papel que juega el ejercicio de la legalidad en los flujos de capitales, ya que en este caso se tiene la opción de tratados internacionales para mejorar la calidad de éste. En la sección 3.6 se trata este punto empíricamente a la luz de los diversos tratados en los que ha participado México a raíz del TLCAN ${ }^{4}$.

Cuadro 1

\begin{tabular}{lccccc}
\multicolumn{6}{c}{ Cuadro 1 } \\
\multicolumn{5}{c}{ Comelaciones entre las Variables de Legalidad } \\
\hline & E.S.J. & Corrup & Contratos & Der-prop & Cum-Leg \\
\hline Corrup & $0.79^{*}$ & & & & \\
Contratos & $0.64^{*}$ & $0.84^{*}$ & & & \\
Der-prop & $0.56^{*}$ & $0.67^{*}$ & $0.77^{*}$ & & \\
Cum-Leg & $0.64^{*}$ & $0.85^{*}$ & $0.88^{*}$ & $0.76^{*}$ & \\
Exprop & $0.66^{*}$ & $0.84^{*}$ & $0.96^{*}$ & $0.74^{*}$ & $0.91^{*}$ \\
\hline *Significativa al 1\% & & & & &
\end{tabular}

\footnotetext{
${ }^{4}$ Además, en una investigación todavía en proceso se realiza este mismo análisis considerando una muestra amplia de países que han participado en este tipo de tratados.
} 
Dicho lo anterior es importante enfatizar la alta correlación que existe entre el nivel de desarrollo de un país en términos de PIB per cápita y la calidad de las instituciones encargadas de la impartición de justicia (ver Gráficas 1 a 3).

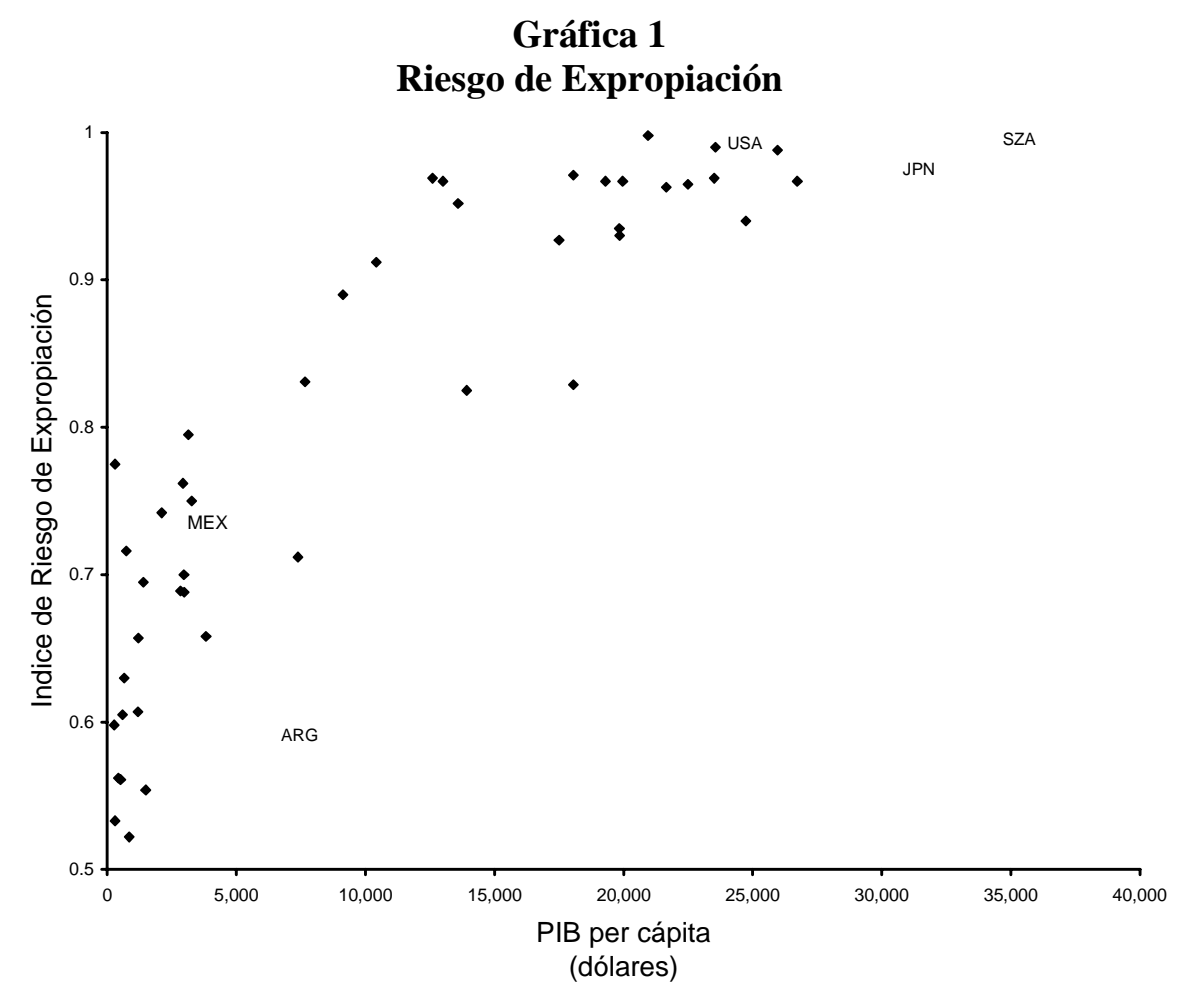

Gráfica 2

Riesgo de Repudiar Contratos

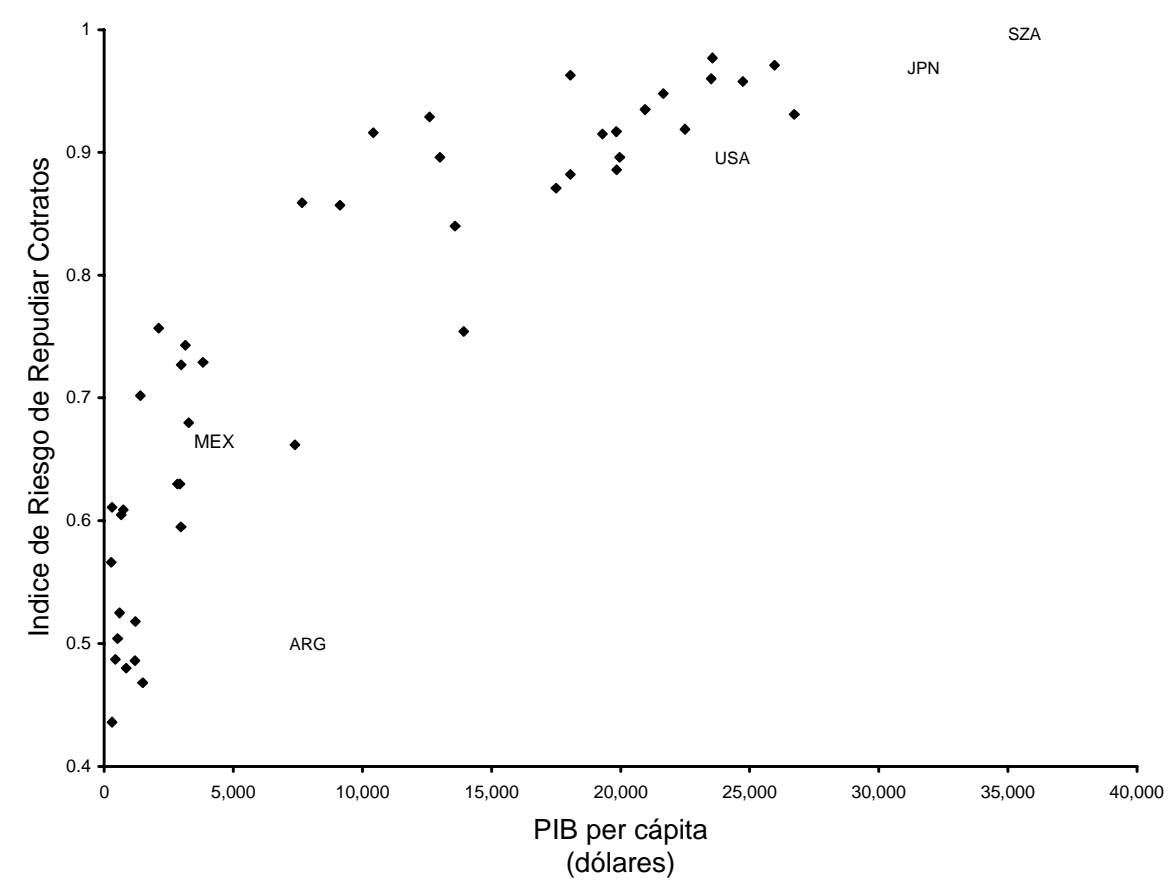




\section{Gráfica 3}

Cumplimiento de la Legalidad

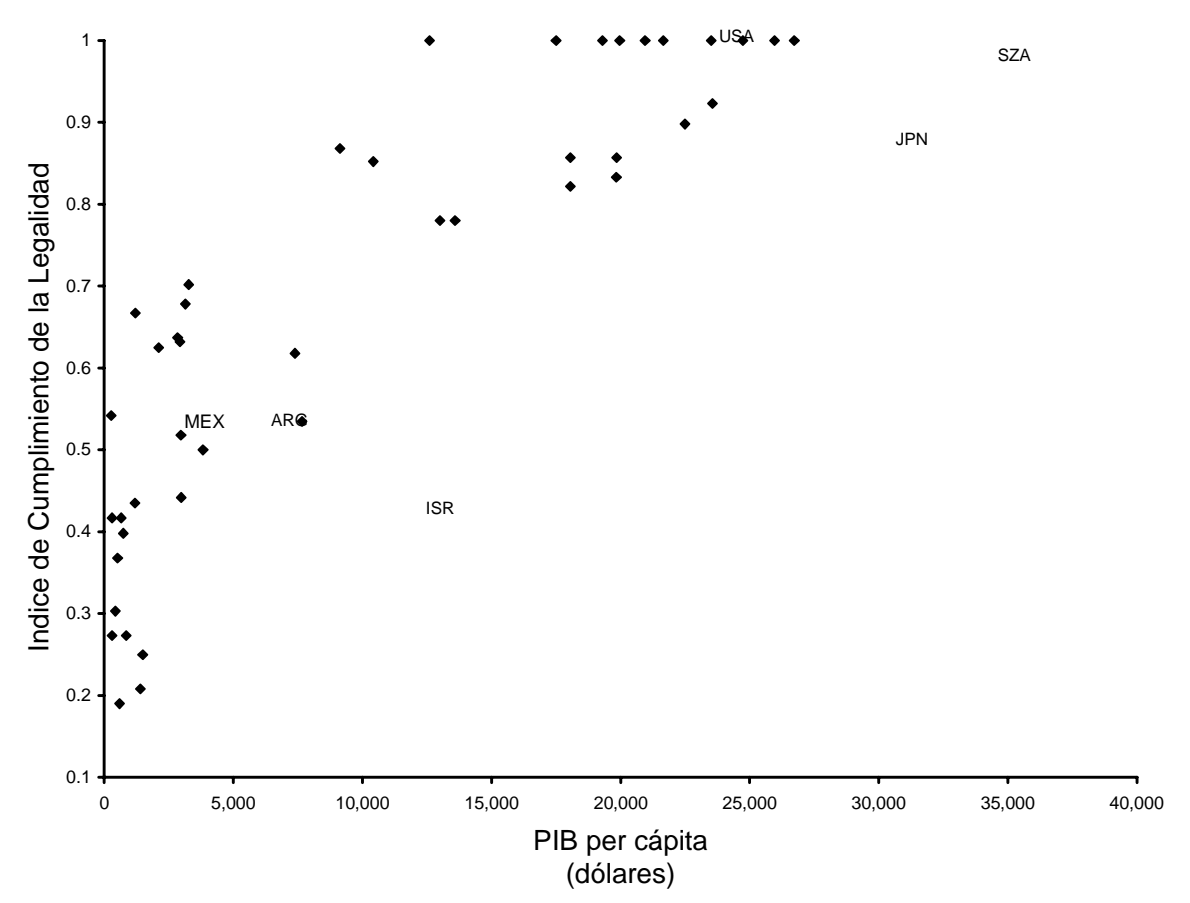

En cuanto a las variables que miden la protección a acreedores utilizadas por LLSV (1998), éstas pueden dividirse en dos grupos:

1. Medidas encaminadas a proteger directamente a los acreedores garantizados.

- Se impone la restricción de tener el consentimiento de los acreedores para solicitar la reorganización ${ }^{5}$ de las empresas (Reorgan). Esta restricción protege a los acreedores contra deudores que buscan la reestructura para evitar que estos últimos enajenen sus garantías.

- Los acreedores garantizados pueden tomar su garantía una vez que se aprobó la petición de reorganización (Garantía).

\footnotetext{
${ }^{5}$ A lo largo del trabajo se emplea el término reorganización para describir el proceso legal que lleva a cabo una empresa que no puede seguir haciendo frente a sus deudas. Para el caso de los EUA este proceso es la única opción para evitar la quiebra. En otros países se realiza un sólo proceso, el cual puede llevar a la liquidación o bien a una reestructura que permita continuar la operación. En México a este proceso se le llama de conciliación.
} 
- Los acreedores garantizados gozan de prelación en el proceso de disposición de activos de una empresa quebrada (Prelación).

- El deudor no mantiene la administración de su propiedad después de solicitar la reorganización (Admon).

2. Medidas indirectas de protección.

- Reserva legal o capital mínimo requerido para evitar que se disuelva una empresa (Reserva).- Esta regulación busca evitar dos tipos de comportamiento que redundan en perjuicio de los acreedores y que son comunes cuando la empresa cuenta con muy poco capital. Primero, que se tomen decisiones demasiado riesgosas, y segundo, que se extraigan por completo los recursos de una empresa cuando se percibe un riesgo de quiebra alto. Esta variable toma el valor de la reserva mínima exigida o de cero si no existe restricción alguna.

Al analizar las correlaciones entre las distintas medidas en el Cuadro 2, se aprecia que todas tienen correlaciones positivas aunque pequeñas, con excepción de la reserva legal la cual presenta una correlación negativa con las demás medidas. Esto puede reflejar que la reserva legal es un mecanismo para cubrir deficiencias en la regulación, o bien en el sistema legal en general, en cuanto a la protección a acreedores garantizados.

Además se calcularon algunos índices combinando algunas de las variables mencionadas:

1. Icred1, es el índice tomado por LLSV (1997) y que incluye todas las medidas directas de protección a acreedores (Icred1 = Reorg + Garantía + Prelación + Admon).

2. Icred2, es el índice tomado por Levin y Zervos (1998) (Icred2 = Garantía + Prelación + Admon).

3. Icred3, contiene las medidas que resultaron significativas (Icred3 = Prelación + Admon). 


\section{Cuadro 2}

\begin{tabular}{lcccc}
\multicolumn{5}{c}{ Correlaciones entre las Medidas de Protección a Acreedores } \\
\hline & Garantías & Prelación & Reorgan & Admon \\
\hline Prelación & $0.26^{*}$ & & & \\
Reorgan & $0.45^{* * *}$ & 0.22 & & \\
Admon & $0.58^{* * *}$ & 0.11 & $0.38^{* * *}$ & \\
Reserva & -0.04 & -0.04 & $-0.29^{* *}$ & -0.18 \\
\hline
\end{tabular}

*Significativa al 10\%

**Significativa al $5 \%$

*** Significativa al $1 \%$

En términos de la protección a accionistas minoritarios, LLSV (1997) consideran, por un lado, las regulaciones directamente enfocadas a proteger a los accionistas minoritarios y, por otro, las que imponen disciplina a los administradores y accionistas mayoritarios a manera de reducir los incentivos para llevar a cabo acciones no óptimas para la empresa.

1. Derechos de accionistas minoritarios contra administradores:

- Se permite votar por correo (Correo).

- No se permite que se bloqueen las acciones durante reuniones de consejo (NoBloqueo).

- Se permite el voto de representación proporcional o cumulativo (Voto-Acum).

- Existen mecanismos de protección a accionistas minoritarios ante expropiación por parte de los directores (Min-Oprim).

- Capital mínimo para convocar a consejo igual o menor que 10\% (Llamado).

- Se da prioridad a los accionistas minoritarios para adquirir nuevas emisiones de acciones o derecho de tanto (Der-comp). El propósito de esta medida es que no se diluya a ciertos inversionistas sin que éstos tengan la opción de comprar.

2. Medidas para disciplinar a los administradores y accionistas mayoritarios:

- Se obliga que cada acción ordinaria corresponda a un voto, es decir, un voto por acción (Un-Voto).- Es igual a 1 si se requiere que cada acción ordinaria corresponda 
a un voto y cero en otro caso. Cuando la propiedad coincide con el poder en la toma de decisiones, los intereses del que mantiene el poder estarán más alineados con los de la empresa, reduciéndose así los incentivos a tomar decisiones no óptimas para la empresa.

Un ejemplo de la importancia de esta restricción resulta ser el caso de México, donde desde 1989 implícitamente se han permitido las estructuras accionarias duales. Esto ha llevado a que en general los accionistas controladores mantengan sólo el capital mínimo para poseer el control de la empresa (Babatz, 1997). En estos casos los intereses de los controladores pueden desviarse significativamente de los de la empresa.

- Porcentaje mínimo de reparto de dividendos (Div-Oblig).- Porcentaje del ingreso neto que la empresa está obligada a distribuir como dividendos a los accionistas ordinarios. Es cero si no existe dicha restricción. Mecanismo para garantizar un rendimiento mínimo a los inversionistas. Sin embargo, puede ser ineficiente ya que en ocasiones resulta óptimo reinvertir las ganancias.

- Normas contables (Est-Contables).- Indice creado calificando los balances anuales de al menos tres empresas por país, para el año de 1990, en relación a la inclusión u omisión de 90 conceptos. Estos conceptos caen en siete categorías: información general, estado de resultados, balance general, estado de cambios en la posición financiera, normas contables, información de acciones y otros aspectos especiales. Las compañías utilizadas representan un corte de varios grupos industriales, de manera que las empresas industriales constituyen el $70 \%$ y las financieras el $30 \%$. Fuente: International Accounting and Auditing Trends, Center for International Financial Analyisis \& Research, Inc. 
Afortunadamente estas variables no están muy correlacionadas entre sí (ver Cuadro 3), por lo que es posible incluirlas simultáneamente sin que los resultados se vean afectados por multicolinealidad.

Cuadro 3

C orreleciones entre las medidas de Protección a Accionistas Minoritarios

\begin{tabular}{|c|c|c|c|c|c|c|c|c|}
\hline & Est-C ontables & Un-V oto & Correo & No-Bloqueo & Voto-A cum & Min-O prim & Llamado & D er-comp \\
\hline Un-V oto & -0.17 & & & & & & & \\
\hline Correo & $0.45^{* * *}$ & $-0.26^{*}$ & & & & & & \\
\hline No-Bloqueo & 0.12 & 0.02 & 0.18 & & & & & \\
\hline Voto-A cum & -0.09 & 0.12 & -0.04 & 0.07 & & & & \\
\hline Min-O prim & 0.24 & 0.21 & $0.23^{*}$ & 0.22 & $0.29 * *$ & & & \\
\hline Llamado & $0.38 * * *$ & -0.09 & $0.24 *$ & 0.13 & -0.04 & $0.44^{* * *}$ & & \\
\hline Der-comp & 0.03 & 0.11 & 0.02 & $-0.23 *$ & 0.01 & -0.14 & -0.07 & \\
\hline Div-oblig & $-0.28 *$ & $0.30 * *$ & -0.17 & 0.04 & 0.06 & -0.07 & $0.27 * *$ & 0.18 \\
\hline
\end{tabular}

Además de las variables mencionadas se desarrollaron algunos índices que engloban a algunas de estas variables:

1. Iantidir $1=$ Correo + No-Bloqueo + Voto-Acum + Min-Oprim + Llamado + Der-comp

2. Iantidir2 $=$ No-Bloqueo + Min-Oprim + Der-comp

Una primera revisión de la regulación mexicana, en cuanto a la protección de derechos de acreedores y de accionistas minoritarios utilizadas en el análisis econométrico (Gráfica 4) ${ }^{6}$, muestra que ésta se encuentra entre las más desfavorables para el desarrollo de los mercados financieros, tanto a nivel mundial como en relación a América Latina y con los países que al igual que México tienen un sistema legal de origen civil francés.

\footnotetext{
${ }^{6}$ Se consideran las regulaciones vigentes en 1998. Para el caso de México las reformas recientes a la LCM bajo un criterio estricto, no cambian ninguno de los indicadores. Aunque bajo un análisis un tanto flexible el índice para no permanencia de la administración podría considerarse igual a uno. Así, se encontraría por
} 


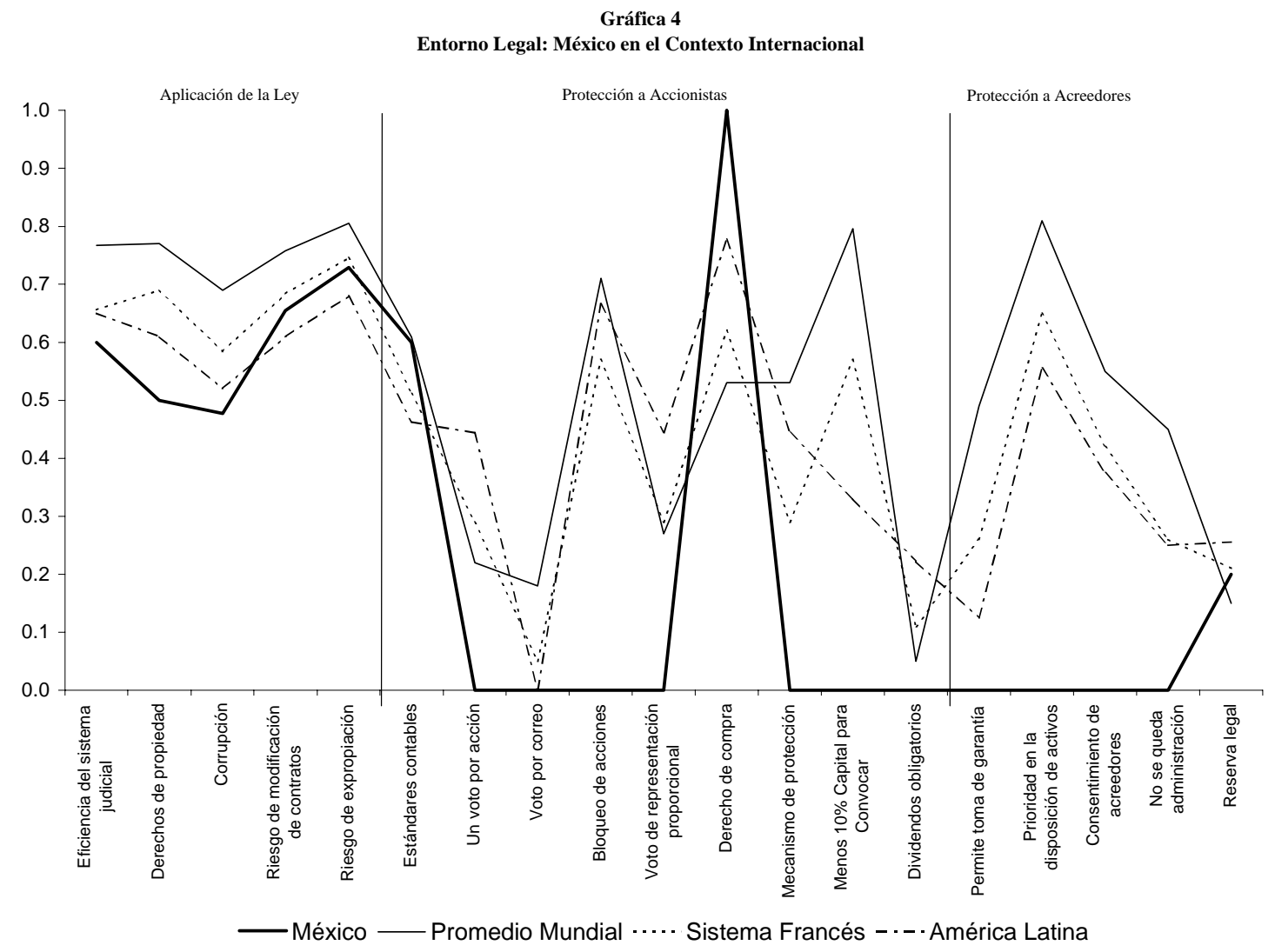

Para medir el desarrollo del mercado crediticio se utilizaron dos medidas alternativas:

1. Endeudamiento total/PIB (Deuda PIB).- Suma de la deuda bancaria del sector privado y emisión de bonos no financieros como proporción del PIB en 1994, o el último dato disponible. Fuente: LLSV, 1997 (con información de International Financial Statistics, World Bondmarket Factbook).

2. Crédito Bancario (Bancaria PIB).- Crédito bancario al sector privado (no-financiero) como proporción del PIB. Promedio de 1976 a 1993. Fuente: Levine y Zervos, 1998 (con información de International Financial Statistics).

Para llevar a cabo el análisis del efecto que tiene la protección de los derechos de propiedad en el mercado de valores es importante determinar cuáles son las medidas que mejor reflejan el desarrollo de este mercado. A este respecto, se cuenta con cuatro variables que

encima de los países latinoamericanos y en general de aquéllos que cuentan con un sistema de origen francés, ya que para ambos casos el promedio se ubica por debajo de 0.3 . 
miden el tamaño del mercado y con otra que determina la liquidez de éste. Como indicadores del tamaño del mercado se utilizaron:

1. Nivel de capitalización Capitalización (Cap). Valor promedio de las acciones nacionales cotizadas en el mercado interno de valores como proporción del PIB. Promedio de 1976 a 1993. Fuente: Levine y Zervos, 1998 (con información de IFC’s Emerging Market Data Base, IMF’s International Financial Statistics).

2. El valor de las Acciones en manos de minoritarios (Externa).- Capitalización del mercado de valores en manos de accionistas minoritarios como proporción del PIB para 1994. La capitalización del mercado de valores en poder de minoritarios se calcula como el producto de la capitalización agregada del mercado de valores y el porcentaje promedio de acciones comunes que no son propiedad de los tres mayores accionistas en las 10 más grandes empresas privadas nacionales no financieras en un país determinado. Una empresa es considerada privada si el Estado no es un accionista conocido de la misma. Fuentes: LLSV, 1997 (con información de Moodys International, CIFAR, EXTEL, WoldScope, 20-Fs, Price-Waterhouse y varias fuentes de los países).

3. Número de empresas cotizadas (Interna).- Número de empresas nacionales cotizadas en un país determinado dividido por la población (en millones) del mismo país en 1994. Fuente: LLSV, 1997 (con información de Emerging Market Factbook y World Development Report 1996).

4. Número de ofertas públicas iniciales de títulos en un país determinado dividido entre la población (en millones) del mismo país para el periodo de julio de 1995 a junio de 1996 (IPOspob). Fuente: LLSV, 1997 (con información de Securities Data Corporation, Asia Money, Latin Finance, GT Guide to World Equity Markets y World Development Report 1996).

Para medir la liquidez del mercado de valores se tomó el valor total de las acciones nacionales comerciadas en el mercado de valores como proporción del PIB (VTC). Promedio de 1976 a 1993. Fuente: Levine y Zervos, 1998.

En el Cuadro 4 se muestra el desarrollo del sistema financiero en México, en términos de los indicadores mencionados, en comparación con el resto del mundo. México se encuentra 
por abajo del desarrollo mundial en todos los indicadores excepto con respecto al endeudamiento de las empresas grandes como proporción de sus ventas y en términos de la inversión extranjera directa como proporción del PIB. Incluso al comparar con Latinoamérica México se encuentra rezagado, a excepción de las variables mencionadas anteriormente y en términos del endeudamiento total del sector privado, del valor operado total y de la inversión de cartera. Sin embargo, es importante notar que para las variables de endeudamiento, la cifra corresponde a 1994, año en el cual México se encontraba en un nivel anormalmente alto, por lo que es posible que de tomarse un período más amplio como referencia México también se encuentre rezagado en este aspecto. En el cuadro también se presentan otras cifras relativas a México para 1998. En general, se aprecia que los indicadores del mercado de valores muestran un avance de 1994 a 1998 mientras que, como es bien sabido, los correspondientes al mercado crediticio se deterioraron.

\section{Cuadro 4}

\section{Desarrollo de Sistema Financiero Mexicano en el Contexto Internacional}

\begin{tabular}{lcccc}
\hline & $\begin{array}{c}\text { Promedio } \\
\text { Internacional }\end{array}$ & $\begin{array}{c}\text { Promedio } \\
\text { Latinoamérica }\end{array}$ & México & $\begin{array}{c}\text { México } \\
1998\end{array}$ \\
\hline D eudaPIB $^{1}$ & 0.59 & 0.31 & 0.47 & - \\
Bancaria $^{2}$ & 0.83 & 0.34 & 0.24 & 0.18 \\
Cap $^{2}$ & 0.32 & 0.16 & 0.13 & 0.24 \\
Externa $^{1}$ & 0.40 & 0.27 & 0.22 & - \\
Interna $^{1}$ & 21.41 & 7.48 & 2.28 & 2.07 \\
IPO Spop $^{1}$ & 1.02 & 0.09 & 0.03 & 0.04 \\
VTC $^{2}$ & 0.11 & 0.02 & 0.04 & 0.09 \\
D euda-Flujo $^{1}$ & 2.23 & 1.61 & 1.54 & - \\
D euda-Vtas $^{1}$ & 0.27 & 0.35 & 0.66 & - \\
Cap-Flujo $^{1}$ & 0.58 & 0.76 & 0.47 & - \\
Cap-Vtas $^{1}$ & 4.77 & 4.59 & 4.06 & - \\
IED $^{2}$ & 1.10 & 0.94 & 1.19 & 2.47 \\
Portafolio $^{2}$ & 0.43 & 0.62 & 1.52 & -0.67 \\
\hline
\end{tabular}

${ }^{1}$ D ato correspondiente a 1994

${ }^{2}$ Promedio 1976-1993

Fuente: WorldScope para D euda-Flujo, D euda-Vtas, Cap-Flujo y Cap-Vtas. FMI para IED y Portafolio. World Bond Market Factbook para D eudaPIB. Levine-Zervos para Bancaria, Cap y VTC. Emerging Market Factbook y World Development Report 1996 para Interna. Securities D ata Corporation, Asia Money, Latin Finance, GT G uide to World Equity Markets y World D evelopment Report para IPO Spob. Moodys Intemational, CIFAR, EXTEL, WorldScope, 20-Fs, Price-Waterhouse para Externa. 
Las variables utilizadas para estimar el efecto del sector financiero sobre el crecimiento económico se describen a continuación:

1. Revoluciones y golpes de estado, (Rev). Número de revoluciones y golpes de estado. Promedio de la década de 1980. Fuente: Levine y Zervos, 1998 (con información de Arthur S. Banks, 1994).

2. Logaritmo del PIB per cápita de 1976 (LPIBpc). Fuente: Levine y Zervos, 1998 (con información del FMI y el Banco Mundial).

3. Crecimiento del PIB per cápita en términos reales (cPIBpc). Periodo de 1976 a 1993. Fuente: Levine y Zervos, 1998 (con información del FMI).

4. Matriculación (lsec).- Logaritmo de la matrícula en educación secundaria en 1976. Fuente: Levine y Zervos, 1998.

5. Ahorro privado (Ahorro).- Ahorro privado bruto como proporción del PIB. Periodo de 1982 a 1993 para los países catalogados como subdesarrollados, periodo de 1976 a 1993 para el resto de los países. Fuente: Levine y Zervos, 1998.

Otras variables:

1. Endeudamiento de empresas grandes (Deuda-Vtas).- Mediana de la deuda total como proporción de las ventas en 1994 para todas las empresas en un país determinado, según la base de datos WorldScope. Fuente: LLSV, 1997 (con información de WorldScope).

2. Endeudamiento de empresas grandes (Deuda-Flujo).- Misma variable que la anterior pero como proporción del flujo de caja. Fuente: LLSV, 1997 (con información de WorldScope).

3. Capital de empresas grandes en manos de minoritarios (Cap-Vtas).- Mediana de la capitalización del mercado de valores en manos de accionistas minoritarios como proporción de las ventas en 1994 para todas las empresas no financieras en un país determinado, según la base de datos WorldScope. La capitalización del mercado de valores de la empresa $\mathrm{j}$ en poder de minoritarios se calcula como el producto de la capitalización del mercado de valores de la empresa j y del porcentaje promedio de acciones comunes que no son propiedad de los tres mayores accionistas en las 10 más grandes empresas privadas nacionales no financieras en un país determinado. Una 
empresa es considerada privada si el Estado no es un accionista conocido de la misma. Fuente: LLSV, 1997 (con información de WorldScope).

4. Capital de empresas grandes en manos de minoritarios (Cap-Flujo).- Misma variable que la anterior pero como proporción del flujo de caja. Fuente: LLSV, 1997 (con información de WorldScope).

5. Inversión Extranjera Directa (IED).- Flujos de capital en forma de inversión extranjera directa que ingresan a la economía como proporción del PIB. Promedio de 1976 a 1993. Fuente: FMI (datos sobre flujos de capital) y Banco Mundial (datos sobre PIB). Clasificación FMI 78bed.

6. Inversión extranjera de capital en cartera (Cartera).- Títulos de participación de capital (incluye acciones e instrumentos similares) en poder de extranjeros como proporción del PIB. Promedio de 1976 a 1993. Fuente: FMI (datos sobre flujos de capital) y Banco Mundial (datos sobre PIB). Clasificación FMI 78bmd.

\subsection{Efecto de la Protección a Acreedores en el Mercado Crediticio}

En esta sección se presentan los resultados encontrados al estimar el impacto de las distintas medidas de protección para los acreedores sobre el desarrollo del mercado crediticio. Se tomaron el crédito bancario al sector privado como proporción del PIB y la deuda bancaria de empresas más la emisión de bonos no financieros también como proporción del PIB, como medidas alternativas del desarrollo de dicho mercado. Además de las restricciones regulatorias para la protección a acreedores garantizados citadas en el punto anterior, las cuales constituyen las variables de interés, en el modelo se incluyeron las indicadores de la calidad del sistema de impartición de justicia o de estado de derecho a manera de control. Debido a la alta correlación de las diferentes variables que se utilizan para medir el estado de derecho, no puede distinguirse adecuadamente entre cada uno de estos componentes. Después de probar varias alternativas se encuentra que la variable de riesgo de repudiar los contratos tiene el mayor poder explicativo. Sin embargo, es importante aclarar que parte del efecto se debe a su alta correlación con otras variables, tales como la corrupción, el riesgo de expropiación, etc. Para evitar posibles problemas de 
correlación espuria se utilizaron variables instrumentales para la variable de repudio de contratos.

En el Cuadro 5 se presentan los resultados obtenidos utilizando la variable de crédito bancario al sector privado como indicador del desarrollo del mercado crediticio. En la primera columna sólo se incluyen las variables de interés, mientras que en el resto del cuadro se incluye alguna variable para controlar por el cumplimiento de la legalidad. A pesar de que se llevaron a cabo regresiones con las distintas variables de legalidad sólo se muestran las especificaciones para las que la regresión tenía un mayor poder explicativo, resultando el riesgo de repudio de contratos, la corrupción y el riesgo de expropiación los indicadores más apropiados.

En todas las especificaciones se encuentra que el requerimiento de que los acreedores garantizados lleven prelación en el proceso de disposición de activos de una empresa quebrada (Prelación), resulta ser la medida con el impacto más importante, siendo significativa la mayor parte de las veces. El hecho de que la medida de permitir a los acreedores garantizados tomar la garantía una vez que se aprobó la reorganización (Garantía) no tenga efecto alguno puede explicarse por dos factores. El primero, y posiblemente el más importante radica en que más relevante que esta medida es el tiempo que lleva la decisión para aprobar la reorganización, ya que si éste es muy largo o incierto, el permitir que se tomen las garantías no es suficiente para dar protección a los acreedores. El segundo factor consiste en que esta medida puede llevar a que al comenzar el proceso de reorganización los acreedores garantizados busquen recuperar rápidamente su garantía, orillando a la quiebra a empresas para las que la reorganización sin los activos que garantizan a acreedores se hace inviable. Esto puede suceder aun en los casos en los que la empresa es rentable y que por ende, desde el punto de vista social, la reorganización resulta óptima.

En las últimas cinco columnas se incorporaron como variables explicativas índices que incluyen algunas de las cinco medidas de protección. El índice que resulta tener el efecto más significativo es el que considera únicamente la prelación de acreedores y la obligación de quitar al administrador una vez que se solicita la reorganización (Icred3). Sin embargo, 
también resulta significativo Icred2, que incluye además el que se permita tomar las garantías en la reorganización.

Cuadro 5

Efecto de la Proteccióna a Acreedores sobre el C rédito Bancario

\begin{tabular}{|c|c|c|c|c|c|c|c|c|c|}
\hline & (1) & $(2)$ & (3) & (4) & (5) & (6) & (7) & $(8)$ & (9) \\
\hline Constante & $\begin{array}{c}0.53^{* * *} \\
(0.19)\end{array}$ & $\begin{array}{c}-0.88^{* * *} \\
(0.25)\end{array}$ & $\begin{array}{c}-1.22 * * * \\
(0.32)\end{array}$ & $\begin{array}{l}-0.36 \\
(0.24)\end{array}$ & $\begin{array}{c}-0.85 * * * \\
(0.20)\end{array}$ & $\begin{array}{c}-0.87 * * * \\
(0.20)\end{array}$ & $\begin{array}{c}-0.90^{* * *} \\
(0.21)\end{array}$ & $\begin{array}{c}-0.99 * * \\
(0.38)\end{array}$ & $\begin{array}{c}-1.34^{* * *} \\
(0.32)\end{array}$ \\
\hline Garantías & $\begin{array}{c}0.08 \\
(0.20)\end{array}$ & $\begin{array}{l}-0.02 \\
(0.14)\end{array}$ & $\begin{array}{c}-0.01 \\
(0.14)\end{array}$ & $\begin{array}{c}0.07 \\
(0.16)\end{array}$ & & & & & \\
\hline Prelación & $\begin{array}{c}0.43^{* *} \\
(0.20)\end{array}$ & $\begin{array}{c}0.17 \\
(0.14)\end{array}$ & $\begin{array}{c}0.17 \\
(0.15)\end{array}$ & $\begin{array}{l}0.29 * \\
(0.16)\end{array}$ & & & & & \\
\hline Reorgan & $\begin{array}{l}-0.13 \\
(0.17)\end{array}$ & $\begin{array}{c}-0.08 \\
(0.11)\end{array}$ & $\begin{array}{c}-0.10 \\
(0.12)\end{array}$ & $\begin{array}{c}-0.12 \\
(0.13)\end{array}$ & & & & & \\
\hline Admon & $\begin{array}{l}-0.08 \\
(0.19)\end{array}$ & $\begin{array}{c}0.16 \\
(0.14)\end{array}$ & $\begin{array}{c}0.21 \\
(0.14)\end{array}$ & $\begin{array}{c}0.12 \\
(0.16)\end{array}$ & & & & & \\
\hline Reserva & $\begin{array}{l}-0.01 \\
(0.39)\end{array}$ & $\begin{array}{l}-0.02 \\
(0.26)\end{array}$ & $\begin{array}{c}0.15 \\
(0.27)\end{array}$ & $\begin{array}{c}0.27 \\
(0.31)\end{array}$ & & & & $\begin{array}{c}0.05 \\
(0.27)\end{array}$ & \\
\hline Contratos & & $\begin{array}{c}1.98^{* * *} \\
(0.31)\end{array}$ & & & $\begin{array}{c}2.00^{* * * *} \\
(0.27)\end{array}$ & $\begin{array}{c}1.99 * * * \\
(0.26)\end{array}$ & $\begin{array}{c}2.00^{* * * *} \\
(0.26)\end{array}$ & $\begin{array}{c}1.85^{* * *} \\
(0.58)\end{array}$ & \\
\hline Exprop & & & $\begin{array}{r}2.24^{* * *} \\
(0.37)\end{array}$ & & & & & & \\
\hline Corrup & & & & $\begin{array}{c}1.25^{* * *} \\
(0.27)\end{array}$ & & & & & \\
\hline Icred1 & & & & & $\begin{array}{l}0.04 \\
(0.12)\end{array}$ & & & & \\
\hline Icred2 & & & & & & $\begin{array}{l}0.07 * \\
(0.04)\end{array}$ & & & $\begin{array}{c}0.16^{* * *} \\
(0.04)\end{array}$ \\
\hline Icred3 & & & & & & & $\begin{array}{l}0.13^{*} \\
(0.07)\end{array}$ & $\begin{array}{l}0.14^{*} \\
(0.08)\end{array}$ & \\
\hline LPIBpc & & & & & & & & $\begin{array}{l}0.02 \\
(0.08)\end{array}$ & $\begin{array}{c}0.23 * * * \\
(0.04)\end{array}$ \\
\hline Muestra & 40 & 40 & 40 & 40 & 40 & 40 & 40 & 40 & 40 \\
\hline$\overline{\mathrm{R}}^{2}$ & 0.02 & 0.55 & 0.53 & 0.40 & 0.59 & 0.60 & 0.61 & 0.57 & 0.48 \\
\hline
\end{tabular}

La variable dependiente es el crédito bancario al sector privado, como proporción del PIB.

En paréntesis la desviación estándar.

* Significativa al $10 \%$

** Significativa al $5 \%$

*** Significativa al $1 \%$

Al igual que lo encontrado por otros autores, el requisito de reserva legal no tiene un efecto significativo e inclusive tiene un signo negativo en algunos casos. Como se explicó 
anteriormente posiblemente esto se deba a la correlación negativa de este requisito con la presencia de otras medidas más efectivas. En las últimas dos columnas se incluye el logaritmo del ingreso per cápita al inicio del período, el cual tiene un impacto muy pequeño y no significativo cuando se controla por la legalidad. De lo anterior se desprende que los indicadores del sistema legal captan el efecto del nivel de ingreso además de otros factores. Esto se ve más claramente al comparar la columna seis y la nueve donde se aprecia que el sistema legal tiene un poder explicativo mayor que el del ingreso per cápita .

Si bien los coeficientes estimados de las variables de las medidas legales indican la diferencia promedio en el tamaño del sector bancario entre países que cuentan con la medida en cuestión y los que no, éstos podrían interpretarse como el efecto en el crédito que tendría la inclusión de dicha medida en la regulación de un país. El mismo argumento es aplicable a los coeficientes de los índices de protección (Icred1, Icred2 e Icred3), tomando en cuenta que por construcción en estos casos el impacto es el mismo para cada una de las medidas incluidas en el índice en cuestión. Con base en lo anterior, se encuentra que la magnitud del efecto de incluir ciertas medidas varía entre las diferentes especificaciones. Incluir las medidas de prelación a los acreedores garantizados y de cambio de administrador al solicitar la reorganización, las cuales son las que tienen mayor impacto, aumentaría el crédito bancario al sector privado entre $14 \%$ y $29 \%$ del PIB. Este efecto resulta muy alto especialmente si se considera que actualmente esta cifra para México es de aproximadamente $20 \%$ del PIB. Por ello es importante enfatizar que la desviación estándar de los estimadores es relativamente alta, de tal suerte que el valor mínimo del efecto de acuerdo, al nivel inferior del intervalo de confianza de 90\%, sería de $2 \%$ del PIB. Además de que, debido al amplio margen de error en la estimación en algunas especificaciones, este efecto no resulta significativo.

Al llevar a cabo estimaciones similares para el nivel de endeudamiento del sector privado (Cuadro 6), se obtiene que ahora la medida más importante resulta ser la de no mantener al administrador al solicitar la reorganización, mientras que la de prelación de acreedores garantizados sólo es significativa cuando no se controla por el estado de legalidad. Si un país instrumentara ambas medidas, el endeudamiento del sector privado aumentaría entre 8 y 20 puntos porcentuales del PIB. Al igual que en el caso del crédito bancario, se debe 
señalar que se obtienen intervalos de confianza muy amplios. En este caso el valor mínimo de acuerdo a un intervalo de confianza de $90 \%$ es igual a uno por ciento del PIB.

\section{Cuadro 6}

Efecto de la Protección a Acreedores sobre el Endeudamiento Total

\begin{tabular}{|c|c|c|c|c|c|c|c|}
\hline & (1) & (2) & (3) & (4) & (5) & (6) & (7) \\
\hline Constante & $\begin{array}{c}0.47 * * * \\
(0.14)\end{array}$ & $\begin{array}{l}-0.42^{*} \\
(0.23)\end{array}$ & $\begin{array}{c}-0.69 * * \\
(0.30)\end{array}$ & $\begin{array}{c}-0.11 \\
(0.20)\end{array}$ & $\begin{array}{c}-0.48^{* * *} \\
(0.14)\end{array}$ & $\begin{array}{c}-0.48 * * * \\
(0.14)\end{array}$ & $\begin{array}{c}-0.49 * * * \\
(0.14)\end{array}$ \\
\hline G arantías & $\begin{array}{c}0.01 \\
(0.12)\end{array}$ & $\begin{array}{l}-0.05 \\
(0.09)\end{array}$ & $\begin{array}{l}-0.08 \\
(0.09)\end{array}$ & $\begin{array}{c}0.03 \\
(0.10)\end{array}$ & & & \\
\hline Prelación & $\begin{array}{l}0.21 * \\
(0.12)\end{array}$ & $\begin{array}{l}-0.001 \\
(0.10)\end{array}$ & $\begin{array}{c}0.01 \\
(0.10)\end{array}$ & $\begin{array}{c}0.10 \\
(0.10)\end{array}$ & & & \\
\hline Reorgan & $\begin{array}{c}-0.02 \\
(0.11)\end{array}$ & $\begin{array}{c}-0.01 \\
(0.08)\end{array}$ & $\begin{array}{c}-0.02 \\
(0.08)\end{array}$ & $\begin{array}{l}-0.05 \\
(0.09)\end{array}$ & & & \\
\hline Admon & $\begin{array}{c}0.05 \\
(0.12)\end{array}$ & $\begin{array}{l}0.16^{*} \\
(0.09)\end{array}$ & $\begin{array}{c}0.23 * * \\
(0.10)\end{array}$ & $\begin{array}{c}0.15 \\
(0.10)\end{array}$ & & & \\
\hline Reserva & $\begin{array}{c}-0.40 \\
(0.39)\end{array}$ & $\begin{array}{l}-0.45^{1} \\
(0.28)\end{array}$ & $\begin{array}{c}-0.26 \\
(0.29)\end{array}$ & $\begin{array}{l}-0.16 \\
(0.33)\end{array}$ & & & \\
\hline Contratos & & $\begin{array}{c}1.32^{* * *} \\
(0.31)\end{array}$ & & & $\begin{array}{c}1.26^{* * *} \\
(0.19)\end{array}$ & $\begin{array}{c}1.26^{* * *} \\
(0.19)\end{array}$ & $\begin{array}{r}1.25^{* * *} \\
(0.19)\end{array}$ \\
\hline Exprop & & & $\begin{array}{c}1.51^{* * * *} \\
(0.37)\end{array}$ & & & & \\
\hline Corrup & & & & $\begin{array}{c}0.83^{* * *} \\
(0.25)\end{array}$ & & & \\
\hline Icred1 & & & & & $\begin{array}{l}0.04^{*} \\
(0.02)\end{array}$ & & \\
\hline Icred2 & & & & & & $\begin{array}{l}0.06^{*} \\
(0.03)\end{array}$ & \\
\hline Icred3 & & & & & & & $\begin{array}{l}0.10^{*} \\
(0.05)\end{array}$ \\
\hline Muestra & 39 & 39 & 39 & 39 & 39 & 39 & 39 \\
\hline $\mathrm{R}^{2}$ & 0.01 & 0.50 & 0.47 & 0.35 & 0.51 & 0.52 & 0.53 \\
\hline
\end{tabular}

La variable dependiente se refiere a la deuda bancaria más la emisión de bonos no financieros, como proporción del PIB.

En paréntesis la desviación estándar.

${ }^{1}$ Significativa al $12 \%$, * Significativa al 10\%, **Significativa al 5\%, ***Significativa al $1 \%$. 
El efecto de la nueva LCM en México puede ser importante, especialmente si se considera que actualmente el crédito bancario al sector privado representa el 18\% del PIB y el endeudamiento total del sector privado se estima en alrededor de $23 \%$ del $\mathrm{PIB}^{7}$. En la nueva legislación aprobada en abril del presente año se incluyen algunas reformas que se acercan a las categorías de protección mencionadas ${ }^{8}$. De acuerdo con el análisis aquí presentado el impacto de estas medidas sobre el crédito bancario podría ser de hasta 14\% del PIB y de hasta $10 \%$ del PIB para el endeudamiento total del sector privado 9 .

Un problema de las estimaciones anteriores es que suponen un impacto lineal de las medidas legales. Resulta más realista pensar que para aquellos países que cuentan con instituciones más eficientes las regulaciones para proteger a los acreedores se aplican mejor y, por ende, tienen un mayor impacto en el mercado crediticio. Dyck (2000) ha criticado el énfasis otorgado a la regulación en la literatura de desarrollo del sistema financiero. Dicho autor argumenta que las leyes no tendrán impacto alguno mientras no se tenga un sistema judicial que las haga valer. También presenta evidencia anecdótica y referencias de la literatura que respaldan este argumento. Para probar esta hipótesis empíricamente, a continuación se utilizan los distintos indicadores del estado de la legalidad, corrupción, etc. para crear variables binarias que se interactuaron con las variables de protección de derechos. Estas variables binarias toman el valor de uno cuando se tiene un buen cumplimiento de la legalidad.

Se realizaron varias especificaciones, combinando los tres índices de protección a los acreedores garantizados con variables binarias de las diferentes variables de legalidad y construidas con distintos criterios. En total se estimaron 36 especificaciones diferentes y en ninguna se encontró que el efecto para los países con un buen sistema institucional fuera significativamente mayor que el del resto de los países, mientras que en la mitad de los

\footnotetext{
${ }^{7}$ Cifras correspondientes a 1999.

${ }^{8}$ En la sección IV se describen de manera más detallada las reformas incluidas en la LCM.

${ }^{9}$ Suponiendo que la prelación de acreedores garantizados y las condiciones para el cambio de administración durante la conciliación que se establecen en la LCM cumplen con las medidas de prelación y de cambio de administración consideradas en el análisis.
} 
casos se encontró que inclusive era menor aunque no significativo. En 19 casos se encontró que el efecto de la regulación era positivo y significativo sin importar la calidad de las instituciones. En el Cuadro 7 se presentan las especificaciones con mayor poder explicativo (con el resto se encuentran resultados similares). La magnitud y significancia de los coeficientes de los distintos índices y de las variables del sistema legal son muy parecidos a los obtenidos anteriormente.

\section{Cuadro 7}

Efecto de la Protección a A creedores sobre el C rédito Bancario, en Función del Sistema Legal

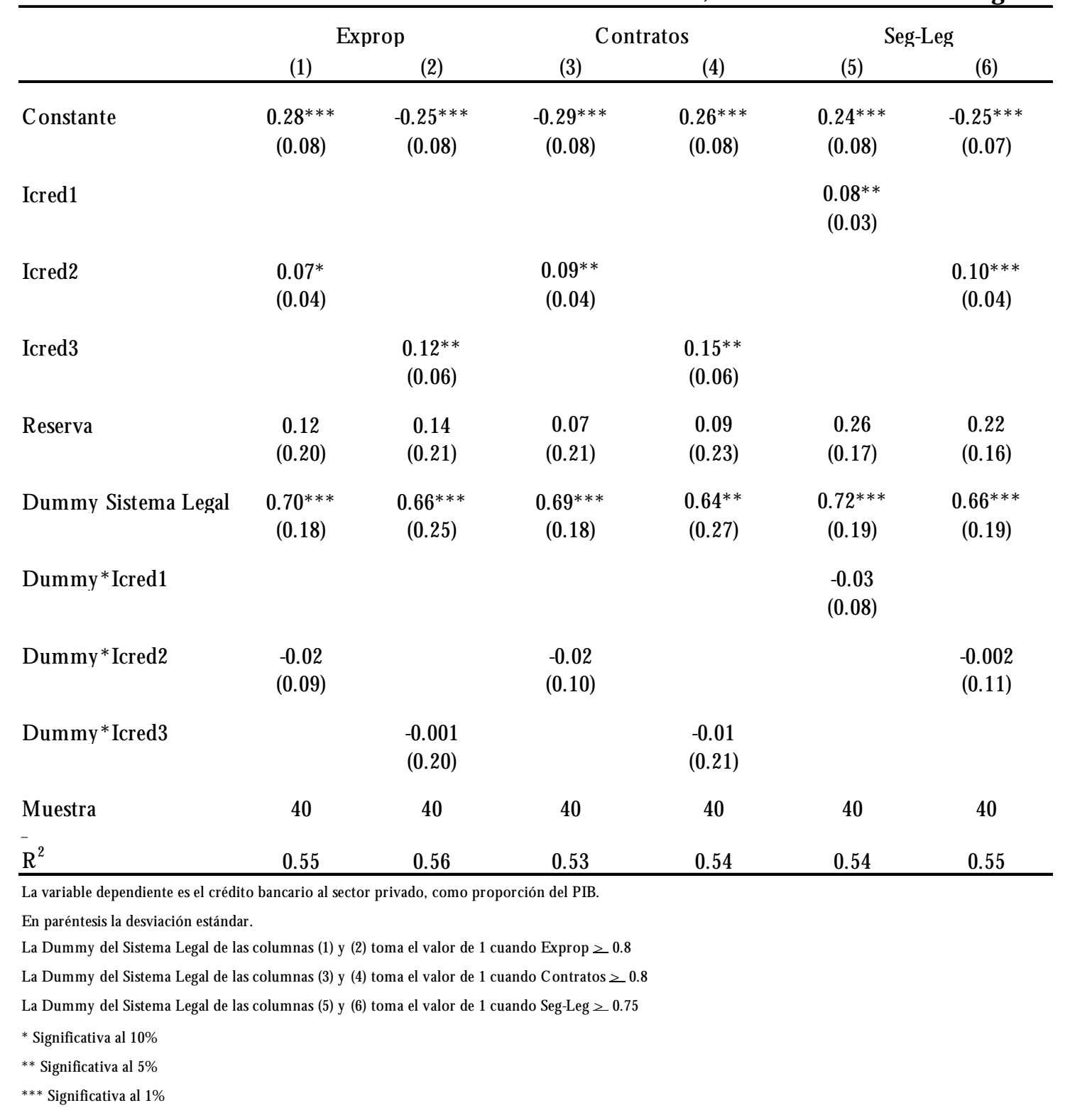


Estos resultados implican que aun en un país como México, con indicadores que muestran un limitado cumplimiento de la legalidad, una regulación adecuada en términos de protección a los acreedores garantizados puede tener un efecto positivo sobre el desarrollo del mercado crediticio.

\subsection{Efecto de la Protección a Accionistas Minoritarios en el Mercado de Valores}

Junto con el mercado crediticio, el mercado de valores o de capital conforma una parte muy importante del sistema financiero. Como se planteó en la segunda sección, sin una regulación adecuada, el problema de agencia, que surge cuando los dueños que controlan una empresa no poseen el cien por ciento de ésta, afectará negativamente el desarrollo del mercado accionario. En esta sección se analizará empíricamente esta hipótesis. Para medir el desarrollo del mercado de capitales se utilizan variables del tamaño de este mercado en términos de su nivel de capitalización, del número de empresas listadas y del número de ofertas públicas iniciales (OPI) y una variable de la liquidez del mercado, en términos del valor operado como porcentaje del PIB.

Para llevar a cabo las estimaciones se tomaron las seis medidas de protección contra directores, además de la obligación de reparto mínimo de dividendos, la restricción de un voto por acción y los lineamientos de estándares contables. En el Cuadro 8 aparecen los resultados de las diferentes especificaciones utilizadas. En todos los casos el impacto de la restricción de un voto por acción es significativo y toma valores de entre 0.24 y 0.34 . Esto es, los países que cuentan con una restricción de este tipo tienen en promedio un mercado de valores mayor en un intervalo de $24-34 \%$ del PIB que aquellos que no cuentan con dicha medida. Las otras medidas que tienen impactos importantes son las de mecanismos de protección contra acciones en perjuicio de socios minoritarios (Min-Oprim), la de obligar el derecho al tanto (Der-Comp) y la prohibición de bloquear las acciones (No-Bloqueo). Aun al controlar por la "calidad del sistema legal" la magnitud y significancia de estos efectos se mantienen. 


\section{C uadro 8}

Efecto de la Protección a A ccionistas Minoritarios sobre el Nivel de C apitalización del Mercado Accionario

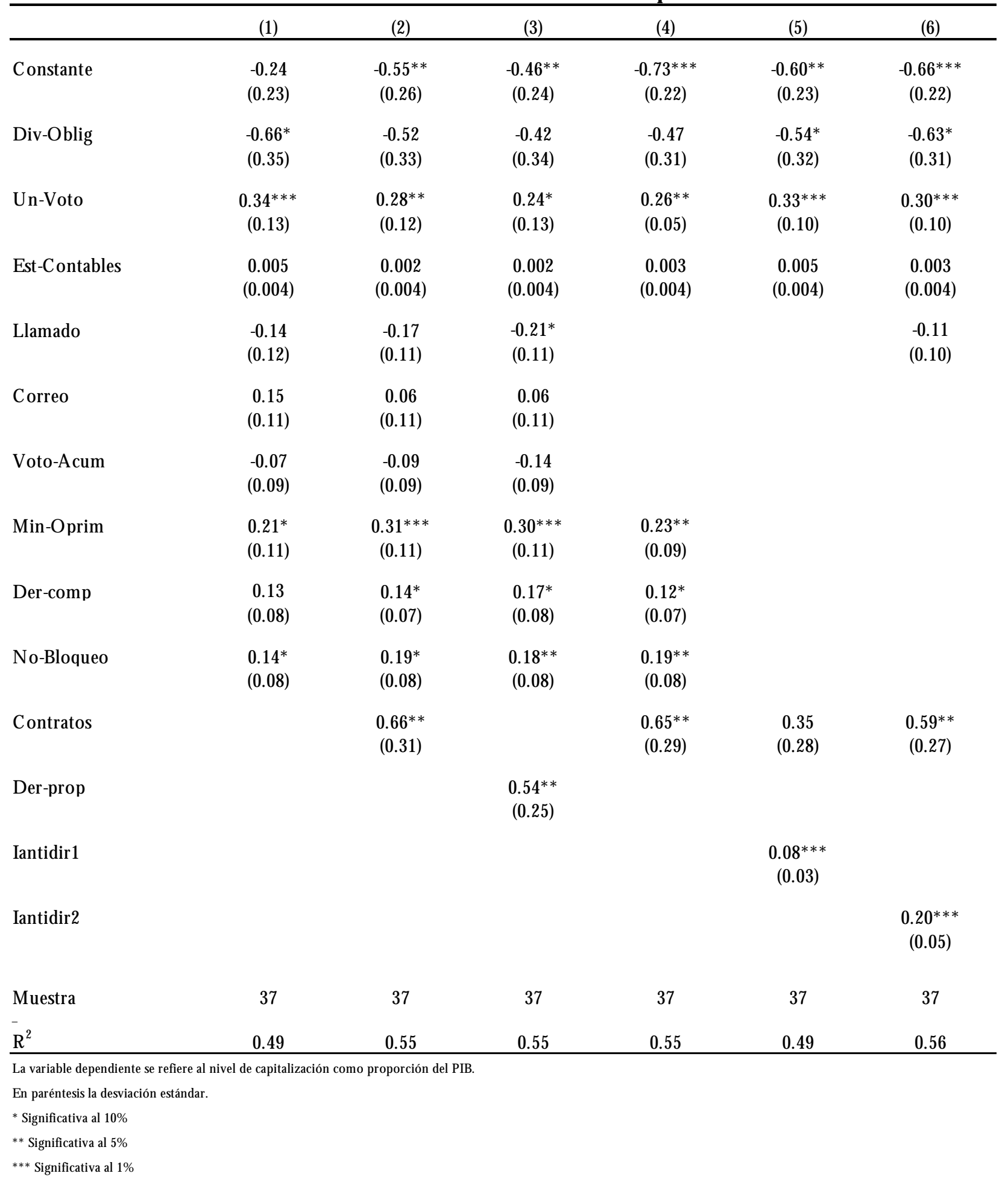

Estos resultados indican que posiblemente sea muy costoso para un accionista minoritario el tener que participar activamente en la toma de decisiones o realizar propuestas para la 
empresa, y resulta más conveniente tener la posibilidad de vender o comprar acciones a un precio adecuado o bien recurrir a la autoridad en caso de malos manejos. De manera que prefieren dichas garantías y la seguridad de que no se va a separar el control de los derechos a utilidades, más que facilitarles su participación en la toma de decisiones.

No es sorprendente que la obligación de repartir un mínimo de dividendos (Div-Oblig) tenga un signo negativo en la capitalización. Como se mencionó anteriormente, generalmente se emite este tipo de acciones cuando se carece de una regulación más eficiente. Ello, ya que a pesar de que esta medida puede conducir a acciones subóptimas para la empresa por impedir la reinversión de utilidades, aun cuando esta práctica es óptima, es más fácil monitorear su cumplimiento que el de otras medidas.

Se construyeron dos índices que engloban algunas de las medidas de protección. El primero, (Iantidir1) incluye las seis medidas mientras que el segundo (Iantidir2) sólo las tres más importantes que se señalaron arriba. Como se muestra en las columnas (5) y (6) del Cuadro 8 ambos resultan significativos y con un impacto muy alto, de $8 \%$ del PIB para el primero y de $18 \%$ del PIB para el segundo. Estos números se traducirían, para el caso de México, donde sólo se cuenta con el derecho de compra, en un aumento del tamaño del sector de entre $36 \%$ y $40 \%$ del PIB. Si se incluye además el efecto de la restricción de voto por acción el impacto sería de entre $66 \%$ y $72 \%$ del PIB. Al interpretar los coeficientes es importante notar que dicho impacto se daría si las medidas incluidas en los índices Iantidir1 y Iantidir2 no están correlacionadas con la restricción de un voto por acción. Debido a que en los datos utilizados en este trabajo la restricción no se cumple, es de esperarse que el efecto total sea menor.

Tal como encuentran LLSV(1997), la alta significancia de las medidas utilizadas y su poder explicativo global, aun sin controlar por otros factores, permite obtener una $\mathrm{R}^{2}$-ajustada de $50 \%$. Lo anterior indica que la protección a socios minoritarios es mucho más importante para el desarrollo del mercado de valores que la protección a acreedores para el mercado de crédito.

Tomando los otros tres indicadores del tamaño del mercado de capitales se obtuvieron resultados similares. En el Cuadro 9 se presentan las estimaciones para estos indicadores, utilizando los índices de protección. Los resultados conseguidos incluyendo cada una de las 
medidas son muy similares a los de la capitalización de mercado. Como es de esperarse el poder explicativo de las variables de interés es mayor para el valor del capital en manos de minoritarios que el total: ahora los índices Iantidir1 y Iantidir2 tienen un impacto de 11\% y $23 \%$ del PIB respectivamente. Si bien la magnitud de estos coeficientes es alta en si misma, resulta más impresionante al considerar que en México el valor del capital en manos de minoritarios es de $22 \%$ del PIB. Esto es, con las medidas propuestas podría llegar a duplicarse el indicador mencionado.

\section{Cuadro 9}

Efecto de la Protección a Accionistas Minoritarios sobre el Mercado de Valores

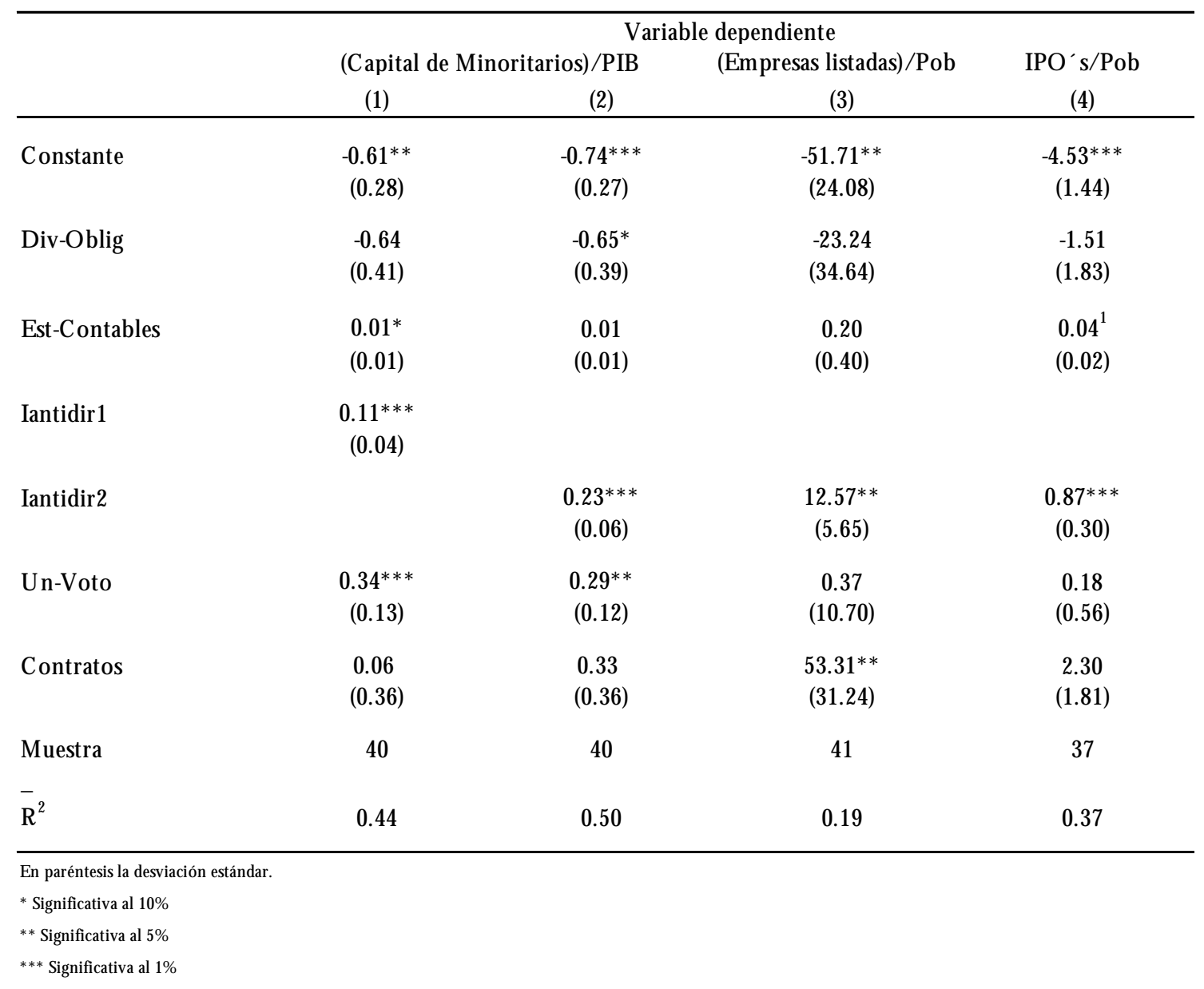

Para los otros indicadores de tamaño de mercado, los índices de las medidas de protección también tienen el signo esperado y son significativos, pero la medida de un voto por acción 
deja de ser significativa. Para el caso del número de empresas listadas y para el número de ofertas públicas iniciales, al igual que con los indicadores anteriores, la magnitud del impacto de las medidas es asombroso, especialmente al ponerlas en perspectiva con las cifras referentes al mercado mexicano. El número de empresas listadas en bolsa como proporción de la población (en millones) es de 2.3, la media correspondiente a todos los países utilizados es de 21.4 y el efecto del índice de protección es de 12.6. Sin embargo, es importante resaltar que el poder explicativo de la regresión no es tan bueno como en el caso de los otros indicadores, lo cual será importante al utilizar estos indicadores como variables instrumentales para el desarrollo del mercado de capitales, para a su vez estimar el efecto de éste sobre el crecimiento económico.

Finalmente, se utilizó la liquidez del mercado de valores como otra proxy del desarrollo de este mercado. Esta variable está dada por el valor de las acciones operadas como proporción del PIB (VTC). En el Cuadro 10 se muestran los resultados de las estimaciones, indicando que únicamente resulta significativa la medida de mecanismos de protección para socios minoritarios. La obligatoriedad de respetar un voto por acción aparece con el signo correcto, pero no resulta significativa.

Al igual que en el caso del mercado crediticio se tomó una especificación más general, que permitiera un efecto no lineal de los derechos de accionistas minoritarios. Para ello, se incluyó un término interactuando el índice de protección de derechos con una variable binaria de la calidad del sistema de justicia, ${ }^{10}$ de modo que se permitiera que la protección de derechos sólo tuviera efecto cuando se contara con instituciones adecuadas. Los resultados encontrados varían mucho bajo las distintas especificaciones, algunas de las cuales aparecen en el Cuadro 11. Se realizaron 12 especificaciones para cada indicador de desarrollo del mercado de valores, dos por cada uno de las seis proxies de seguimiento de la legalidad. Para el nivel de capitalización, el nivel de capitalización en manos de minoritarios y el número de empresas que cotizan, se encontró que sólo en dos casos de cada variable el índice anti-director era significativo para los países con un pobre seguimiento de la legalidad y en tres era significativo el efecto para los demás países.

10 La metodología para la construcción de las variables binarias se presenta en la sección del mercado crediticio. 
Cuadro 10

Efecto de la Protección a Accionistas Minoritarios sobre el Valor Comerciado de las Acciones D omésticas

\begin{tabular}{|c|c|c|c|c|c|}
\hline & (1) & $(2)$ & (3) & (4) & (5) \\
\hline Constante & $\begin{array}{c}-0.11 \\
(0.20)\end{array}$ & $\begin{array}{c}-0.35 \\
(0.22)\end{array}$ & $\begin{array}{c}-0.25 \\
(0.19)\end{array}$ & $\begin{array}{l}-0.31 \\
(0.19)\end{array}$ & $\begin{array}{c}-0.29 \\
(0.20)\end{array}$ \\
\hline Div-O blig & $\begin{array}{c}-0.23 \\
(0.29)\end{array}$ & $\begin{array}{c}-0.17 \\
(0.27)\end{array}$ & $\begin{array}{c}-0.19 \\
(0.26)\end{array}$ & $\begin{array}{c}-0.26 \\
(0.28)\end{array}$ & $\begin{array}{c}-0.25 \\
(0.29)\end{array}$ \\
\hline Un-Voto & $\begin{array}{c}0.05 \\
(0.10)\end{array}$ & $\begin{array}{c}0.04 \\
(0.09)\end{array}$ & $\begin{array}{c}0.03 \\
(0.08)\end{array}$ & $\begin{array}{c}0.08 \\
0.09\end{array}$ & $\begin{array}{c}0.08 \\
(0.09)\end{array}$ \\
\hline Est-Contables & $\begin{array}{c}0.004 \\
(0.003)\end{array}$ & $\begin{array}{r}-0.0001 \\
(0.004)\end{array}$ & $\begin{array}{c}-0.001 \\
(0.004)\end{array}$ & $\begin{array}{c}0.001 \\
(0.003)\end{array}$ & $\begin{array}{c}0.002 \\
(0.004)\end{array}$ \\
\hline Llamado & $\begin{array}{c}0.03 \\
(0.10)\end{array}$ & $\begin{array}{c}-0.01 \\
(0.10)\end{array}$ & & & \\
\hline Correo & $\begin{array}{l}0.002 \\
(0.10)\end{array}$ & $\begin{array}{c}-0.06 \\
(0.10)\end{array}$ & & & \\
\hline Voto-A cum & $\begin{array}{c}0.08 \\
(0.08)\end{array}$ & $\begin{array}{c}0.08 \\
(0.08)\end{array}$ & & & \\
\hline Min-O prim & $\begin{array}{c}0.08 \\
(0.10)\end{array}$ & $\begin{array}{l}0.16^{1} \\
(0.10)\end{array}$ & $\begin{array}{c}0.17 * * \\
(0.07)\end{array}$ & & \\
\hline D er-comp & $\begin{array}{c}-0.07 \\
(0.08)\end{array}$ & $\begin{array}{c}-0.05 \\
(0.07)\end{array}$ & & & \\
\hline No-Bloqueo & $\begin{array}{c}-0.09 \\
(0.08)\end{array}$ & $\begin{array}{c}-0.04 \\
(0.07)\end{array}$ & & & \\
\hline Contratos & & $\begin{array}{c}0.58 * * \\
(0.28)\end{array}$ & $\begin{array}{l}0.43 \\
(0.32)\end{array}$ & $\begin{array}{l}0.37 \\
(0.25)\end{array}$ & $\begin{array}{c}0.35 \\
(0.27)\end{array}$ \\
\hline Iantidir1 & & & & $\begin{array}{l}0.03 \\
(0.03)\end{array}$ & \\
\hline Iantidir2 & & & & & $\begin{array}{l}0.02 \\
(0.05)\end{array}$ \\
\hline Muestra & 38 & 38 & 38 & 38 & 38 \\
\hline$R^{2}$ & 0.06 & 0.16 & 0.21 & 0.08 & 0.05 \\
\hline
\end{tabular}

La variable dependiente se refiere al valor comerciado de las acciones domésticas, como proporción del PIB.

En paréntesis la desviación estándar.

${ }^{1}$ Significativa al $12 \%$

* Significativa al $10 \%$

** Significativa al $5 \%$

*** Significativa al $1 \%$

En el resto de las 21 especificaciones en ningún caso el índice fue significativo. De manera que es difícil sacar conclusiones en cualquier sentido. Para los estándares contables y para la restricción de un voto por acción los resultados fueron más contundentes. Se encuentra que en general tienen un efecto positivo significativo y éste no difiere entre los distintos países independientemente de la calidad de las instituciones. De acuerdo a estos resultados, el impacto en la capitalización de mercado de incluir estas medidas, en un país que no cuenta con instituciones legales sólidas, podría ser de hasta 50\% del PIB. Aunque 
considerando la especificación con el mínimo impacto, para la cual los coeficientes no son significativos, el efecto sería de 5\% del PIB.

Cuadro 11

E fecto de la Protección a Accionistas Minoritarios sobre el Mercado de Valores en Función del Sistema Legal

\begin{tabular}{|c|c|c|c|c|c|c|}
\hline & (Nive & $\begin{array}{r}\text { Varia } \\
\text { Capitaliza }\end{array}$ & $\begin{array}{l}\text { dependie } \\
\text { / PIB }\end{array}$ & (Capi & Minorit & / / PIB \\
\hline & $\begin{array}{l}\text { Cum-Leg } \\
\text { (1) }\end{array}$ & $\begin{array}{l}\text { Cum-Leg } \\
\text { (2) }\end{array}$ & $\begin{array}{c}\text { Corrup } \\
\text { (3) }\end{array}$ & $\begin{array}{l}\text { Cum-Leg } \\
\text { (4) }\end{array}$ & $\begin{array}{c}\text { Corrup } \\
\text { (5) }\end{array}$ & $\begin{array}{l}\text { Der-prop } \\
\quad(6)\end{array}$ \\
\hline Constante & $\begin{array}{l}-0.27 \\
-0.19\end{array}$ & $\begin{array}{l}-0.08 \\
-0.12\end{array}$ & $\begin{array}{l}-0.27 \\
-0.18\end{array}$ & $\begin{array}{l}-0.04 \\
-0.07\end{array}$ & $\begin{array}{l}-0.15 \\
-0.13\end{array}$ & $\begin{array}{c}-0.65^{* *} \\
-0.31\end{array}$ \\
\hline Est-Contables & $\begin{array}{c}0.005 \\
(0.003)\end{array}$ & $\begin{array}{c}0.004 \\
(0.002)\end{array}$ & $\begin{array}{c}0.01^{*} \\
(0.003)\end{array}$ & $\begin{array}{l}0.003^{* *} \\
(0.001)\end{array}$ & $\begin{array}{c}0.01 \\
(0.004)\end{array}$ & $\begin{array}{c}0.01 \text { ** } \\
-0.01\end{array}$ \\
\hline Div-Oblig & $\begin{array}{c}-0.37 * \\
-0.22\end{array}$ & $\begin{array}{l}-0.09 \\
-0.06\end{array}$ & $\begin{array}{l}-0.35 \\
-0.23\end{array}$ & $\begin{array}{l}-0.09 \\
-0.06\end{array}$ & $\begin{array}{c}0.07 \\
-0.26\end{array}$ & $\begin{array}{c}-0.84^{*} \\
-0.41\end{array}$ \\
\hline Un-V oto & $\begin{array}{c}0.24^{* *} \\
-0.10\end{array}$ & $\begin{array}{l}0.05 \\
-0.05\end{array}$ & $\begin{array}{c}0.24^{* *} \\
-0.11\end{array}$ & $\begin{array}{c}0.25^{* * *} \\
-0.02\end{array}$ & $\begin{array}{c}0.32 * * * \\
-0.09\end{array}$ & $\begin{array}{c}0.36 \\
-0.22\end{array}$ \\
\hline Iantidir2 & $\begin{array}{l}0.09 * \\
-0.06\end{array}$ & $\begin{array}{l}-0.01 \\
-0.02\end{array}$ & $\begin{array}{c}0.07 \\
-0.06\end{array}$ & $\begin{array}{c}0.03 \\
-0.03\end{array}$ & $\begin{array}{c}0.05 \\
-0.06\end{array}$ & $\begin{array}{c}0.13 \\
-0.14\end{array}$ \\
\hline $\begin{array}{l}\text { Dummy } \\
\text { Sistema Legal }\end{array}$ & $\begin{array}{l}-0.06 \\
-0.34\end{array}$ & $\begin{array}{l}-0.26 \\
-0.23\end{array}$ & $\begin{array}{c}0.79 \\
-0.75\end{array}$ & $\begin{array}{c}-0.41 * \\
-0.24\end{array}$ & $\begin{array}{c}-0.53^{* *} \\
-0.25\end{array}$ & $\begin{array}{c}0.15 \\
-0.36\end{array}$ \\
\hline D*Est-Contables & $\begin{array}{l}0.001 \\
-0.01\end{array}$ & $\begin{array}{c}0.002 \\
(0.004)\end{array}$ & $\begin{array}{l}-0.01 \\
-0.01\end{array}$ & $\begin{array}{c}0.005 \\
(0.004)\end{array}$ & $\begin{array}{c}0.01 \\
(0.005)\end{array}$ & $\begin{array}{c}-0.005 \\
-0.01\end{array}$ \\
\hline D*Div-Oblig & - & $\begin{array}{c}-1.05 * * * \\
-0.35\end{array}$ & - & $\begin{array}{c}-1.15^{* *} \\
-0.44\end{array}$ & $\begin{array}{c}-1.30^{* *} \\
-0.50\end{array}$ & $\begin{array}{c}0.53 \\
-0.46\end{array}$ \\
\hline D*Un-Voto & $\begin{array}{c}0.21 \\
-0.22\end{array}$ & $\begin{array}{l}0.32 * \\
-0.18\end{array}$ & $\begin{array}{c}0.14 \\
-0.25\end{array}$ & $\begin{array}{c}0.17 \\
-0.19\end{array}$ & $\begin{array}{c}0.13 \\
-0.21\end{array}$ & $\begin{array}{l}-0.20 \\
-0.24\end{array}$ \\
\hline D*Iantidir2 & $\begin{array}{r}0.09 \\
-0.12\end{array}$ & $\begin{array}{l}0.18^{*} \\
-0.09\end{array}$ & $\begin{array}{c}0.22 \\
-0.15\end{array}$ & $\begin{array}{c}0.17 * * \\
-0.08\end{array}$ & $\begin{array}{c}0.13 \\
-0.10\end{array}$ & $\begin{array}{l}-0.01 \\
-0.15\end{array}$ \\
\hline Muestra & 37 & 37 & 37 & 38 & 38 & 37 \\
\hline$\overline{\mathrm{R}}^{2}$ & 0.65 & 0.68 & 0.71 & 0.67 & 0.65 & 0.66 \\
\hline
\end{tabular}

En paréntesis la desviación estándar.

La D ummy del Sistema Legal de la columna (1) toma el valor de 1 cuando Seg-Leg $\geq 0.75$

La D ummy del Sistema Legal de las columnas (2) y (4) toma el valor de 1 cuando Seg-Leg $\geq 0.6$

La D ummy del Sistema Legal de la columna (3) toma el valor de 1 cuando Corrup $\geq 0.8$

La D ummy del Sistema Legal de la columna (5) toma el valor de 1 cuando Corrup $\geq 0.6$

La D ummy del Sistema Legal de la columna (6) toma el valor de 1 cuando D er-prop $\geq 0.8$

* Significativa al 10\%, ** Significativa al 5\%, *** Significativa al 1\% 
Anteriormente se mencionó la evidencia que presentan Bhattacharya et al (2000) en torno al uso de información privilegiada en México. Sus resultados reflejan la importancia que tiene la calidad de las instituciones de procuración de justicia en este ámbito, ya que en este caso a pesar de contar con una regulación que prohiba este tipo de comportamiento, nunca se ha acusado o juzgado a alguien por el uso de información privilegiada.

También se realizaron estimaciones similares para las ofertas públicas iniciales y para el valor comerciado, pero se encontraron resultados aún más ambiguos y con un poder explicativo de las regresiones muy bajo, especialmente para las regresiones con la última variable.

A continuación se evalúan dos críticas potenciales a las estimaciones presentadas. La primera crítica a considerar es la siguiente:

La relación entre la regulación y el desarrollo del mercado de valores se debe a una correlación espuria por no incluir el nivel de ahorro.

Otra preocupación en cuanto al efecto de los derechos de propiedad en el mercado de valores es que sería posible que los países que tienen un mayor nivel de ahorro son aquéllos que han desarrollado más este mercado, no por el entorno legal sino por la demanda de instrumentos de ahorro. Para determinar la importancia de este efecto y corroborar que los resultados presentados no se ven afectados por este fenómeno, se realizaron primero correlaciones simples entre el nivel de ahorro como proporción del PIB y los distintos indicadores de protección a accionistas, incluyendo un indicador que agrega todas las variables. En el Cuadro 12 se ve que no existe una correlación positiva entre las variables de interés y el nivel de ahorro. También se incluyó el ahorro como proporción del PIB en las regresiones de los determinantes del desarrollo del mercado de valores (Cuadro 13). Aun sin corregir por la posible endogeneidad del ahorro, problema que tendería a sesgar el coeficiente de dicha variable hacia una relación positiva, se obtiene que los coeficientes de las variables de interés no cambian y que el ahorro no es significativo. 
Cuadro 12

Correlación entre el Nivel de Ahorro y la Protección de Derechos de Propiedad

\begin{tabular}{cccc}
\hline $\begin{array}{c}\text { Protección a Accionistas } \\
\text { Minoritarios }\end{array}$ & \multicolumn{3}{c}{ Protección a Acreedores } \\
\hline Iantidir1 & $-0.38^{* *}$ & Icred1 & -0.17 \\
Iantidir2 & $-0.42 * *$ & Icred2 & -0.02 \\
Est-Contables & -0.22 & Icred3 & 0.10 \\
Un-Voto & 0.22 & G arantías & -0.14 \\
Correo & -0.22 & Prelación & 0.05 \\
No-Bloqueo & $-0.49 * * *$ & Reorgan & $-0.39 * *$ \\
Voto-Acum & -0.10 & Admon & 0.08 \\
Min-O prim & -0.21 & Reserva & 0.27 \\
Llamado & -0.10 & & \\
D er-comp & -0.02 & & \\
Div-O blig & -0.15 & & \\
\hline * Significativa al 10\%, $* *$ Significativa al $5 \%, * * *$ Significativa al $1 \%$ & & \\
$* *$ Significativa al $5 \%$ & & & \\
$* * *$ Significativa al $1 \%$ & & &
\end{tabular}

Cuadro 13

Efecto de la Protección a Acreedores y del Nivel de Ahorro sobre el Nivel de Capitalización

\begin{tabular}{|c|c|c|c|c|c|c|}
\hline & (1) & (2) & (3) & (4) & (5) & (6) \\
\hline Constante & $\begin{array}{l}-0.37 \\
-0.36\end{array}$ & $\begin{array}{c}-0.49 * \\
-0.26\end{array}$ & $\begin{array}{l}-0.32 \\
-0.30\end{array}$ & $\begin{array}{c}-0.59 * * \\
-0.25\end{array}$ & $\begin{array}{l}-0.46 \\
-0.41\end{array}$ & $\begin{array}{l}-0.38 \\
-0.35\end{array}$ \\
\hline Ahorro/ PIB & $\begin{array}{c}0.0001 \\
-0.01\end{array}$ & & $\begin{array}{l}-0.004 \\
-0.01\end{array}$ & & $\begin{array}{l}0.005 \\
-0.01\end{array}$ & $\begin{array}{r}-0.0004 \\
-0.01\end{array}$ \\
\hline Contratos & $\begin{array}{c}0.34 \\
-0.24\end{array}$ & $\begin{array}{c}0.44 \\
-0.28\end{array}$ & $\begin{array}{c}0.39 \\
-0.26\end{array}$ & $\begin{array}{c}0.58^{* *} \\
-0.27\end{array}$ & $\begin{array}{c}0.39 \\
-0.26\end{array}$ & $\begin{array}{c}0.43 \\
-0.27\end{array}$ \\
\hline Icred1 & $\begin{array}{c}0.03 \\
-0.03\end{array}$ & $\begin{array}{l}0.05^{*} \\
-0.03\end{array}$ & & $\begin{array}{l}0.04 \\
-0.03\end{array}$ & $\begin{array}{c}0.02 \\
-0.03\end{array}$ & \\
\hline Icred3 & & & $\begin{array}{c}0.07 \\
-0.06\end{array}$ & & & $\begin{array}{l}0.06 \\
-0.07\end{array}$ \\
\hline Un-Voto & $\begin{array}{c}0.21 * * \\
-0.09\end{array}$ & $\begin{array}{c}0.18^{*} \\
-0.10\end{array}$ & $\begin{array}{c}0.20^{* *} \\
-0.08\end{array}$ & $\begin{array}{c}0.14 \\
-0.09\end{array}$ & $\begin{array}{l}0.18^{*} \\
-0.10\end{array}$ & $\begin{array}{c}0.18^{*} \\
0.09\end{array}$ \\
\hline Iantidir1 & $\begin{array}{c}0.08^{* * *} \\
-0.03\end{array}$ & $\begin{array}{c}0.09 * * * \\
-0.03\end{array}$ & $\begin{array}{l}0.07 * \\
-0.03\end{array}$ & & & \\
\hline Iantidir2 & & & & $\begin{array}{c}0.17^{* * *} \\
-0.05\end{array}$ & $\begin{array}{c}0.13^{* *} \\
-0.05\end{array}$ & $\begin{array}{c}0.12^{* *} \\
-0.06\end{array}$ \\
\hline Muestra & 29 & 39 & 29 & 39 & 29 & 29 \\
\hline$\overline{\mathrm{R}}^{2}$ & 0.49 & 0.41 & 0.54 & 0.48 & 0.41 & 0.48 \\
\hline $\begin{array}{l}\text { La variable dependi } \\
\text { En paréntesis la des }\end{array}$ & al nivel de c & & & \multicolumn{3}{|c|}{$\begin{array}{l}* * \text { Significativa al } 5 \% \\
* * * \text { Significativa al } 1 \%\end{array}$} \\
\hline
\end{tabular}


La segunda crítica a evaluar es la siguiente:

Una mayor protección a acreedores garantizados implica una desprotección a accionistas ya que resulta más difícil una reestructura. Por ende, el mercado de valores podría verse negativamente afectado por este tipo de regulación.

Un aspecto importante a considerar es que en muchas ocasiones, al proteger los derechos de los acreedores, se actúa en contra de los accionistas. Esto es, la protección a los acreedores garantizados, como se analizó anteriormente, puede tener un efecto negativo sobre el mercado de valores ya que al favorecer a los acreedores cuando la empresa no puede pagar y permitir la toma del colateral, necesariamente se perjudica a los accionistas. Sin embargo, también podría darse el efecto de que la protección a los acreedores genera un desarrollo eficiente del sistema bancario o crediticio, esto es, que realice una labor de vigilancia o bien que sólo preste a las empresas que llevan a cabo proyectos rentables. De esta manera los accionistas minoritarios pueden aprovechar la vigilancia que realizan los bancos, invirtiendo en empresas que tienen créditos. Este segundo enfoque, utilizado en la literatura, no es muy claro ya que aquí se está considerando la protección a los acreedores garantizados y debido a que el valor de mercado de la garantía en general es mayor que el crédito, el banco no tiene mayor interés en vigilar a la empresa sino simplemente se asegura de que podrá tomar el activo en caso de no pago.

En el Cuadro 13 también se muestra la inclusión del índice de protección a acreedores en las regresiones del desarrollo del mercado accionario encontrándose que el efecto es positivo y significativo en una de las especificaciones. De modo que si los derechos otorgados a acreedores afectan en algún sentido al desarrollo del mercado de capitales este impacto será positivo. En consecuencia, una mejor definición de los derechos de propiedad ayuda a que la negociación lleve al resultado óptimo para la empresa, favoreciendo a los accionistas. Al parecer este efecto resulta más importante que el de asignar mayor poder a los acreedores.

\subsection{Efecto sobre el Crecimiento Económico}

Para determinar el efecto de los mercados financieros sobre el crecimiento económico se estima el modelo usual en este campo, tomando como variable dependiente el crecimiento 
promedio por país en un período específico. Las variables explicativas constan de alguno de los indicadores del desarrollo del sistema financiero mencionados anteriormente y variables de control tales como el ingreso per cápita, el nivel de educación, el nivel de salud, la estabilidad política y el ejercicio de la legalidad. La muestra utilizada consta de 40 países durante el período de 1980 a 1993.

El estudio del impacto del desarrollo de los mercados financieros sobre el crecimiento económico resulta muy complicado desde un punto de vista empírico. Ello, debido a que se presenta el problema de causalidad recíproca ya que es muy difícil solucionar el problema de correlación espuria. El problema de causalidad recíproca se da cuando dos variables se determinan simultáneamente. En el caso aquí examinado, esto se presenta debido a que un sistema financiero más desarrollado contribuye a que se canalice el ahorro de una manera eficiente hacia los proyectos más rentables a un costo mínimo. De esta manera se incentiva la inversión y en última instancia se producen mayores tasas de crecimiento económico. Pero también un país que crece más rápido puede generar mayores oportunidades de inversión o bien puede lograr a un mayor ahorro, o dar lugar a otros aspectos que impliquen mayores recursos al sistema financiero y que, por ende, contribuyan a que éste se desarrolle.

El problema de correlación espuria se da cuando no se incluye en el análisis una variable relevante que afecte a las variables de interés y por su omisión se concluye erróneamente que una de las variables aquí utilizadas determina la otra. En el caso particular de la relación del sistema financiero con el crecimiento económico existe una gran cantidad de variables que afectan tanto al desarrollo del sistema financiero como al crecimiento económico, tales como las oportunidades de inversión, el nivel educativo y el nivel de salud, entre otras.

Ambos problemas son difíciles de resolver, por lo que a pesar de que este aspecto se ha analizado ampliamente en la literatura económica no es fácil encontrar estimaciones satisfactorias. Afortunadamente, existe una alternativa para solucionar este problema. Es preciso encontrar alguna variable que afecte el desarrollo del sistema bancario y del mercado de valores, pero que sólo incida sobre el crecimiento económico indirectamente, a través de dicha variable y no de manera directa. Si se tiene esta variable, es posible aislar 
las diferencias en el desarrollo del sistema bancario que no obedecen a mayores tasas de crecimiento económico y, por medio de técnicas econométricas, estimar el impacto que éstas tienen sobre el crecimiento económico futuro de un país.

Las variables del entorno legal en cuanto a la protección de derechos, propuestas por LLSV (1997), resultan ser muy adecuadas para resolver los problemas de causalidad recíproca y de correlación espuria. Las medidas de protección resuelven problemas de incentivos que son muy importantes para el desarrollo de los mercados financieros, pero además tienen la ventaja de que son principalmente determinadas por la tradición legal de la que provienen las leyes del país: sistema legal civil o común, y que no se ven afectadas por el desarrollo económico del país. De modo que cumplen las características requeridas para ser usadas como variables instrumentales del desarrollo del sistema financiero.

Se podría pensar que la presencia de incentivos tan perversos llevaría a entornos legales muy similares entre países Sin embargo, se observa una gran disparidad tanto en lo que respecta a la regulación para proteger a los inversionistas en contra de expropiación por parte de los administradores o accionistas mayoritarios, como en la regulación para proteger a acreedores. Estas disparidades legales se deben más que nada a la tradición legal de los países.

Este punto puede observarse en las Gráficas 5 y 6 al notar la falta de relación alguna entre el nivel de ingreso y la regulación. Esto implica que el impacto que tiene la regulación en el desarrollo del sistema financiero y en última instancia en el crecimiento económico no puede atribuirse a problemas de correlación espuria con el ingreso. Por otro lado, esta falta de correlación también implica que las condiciones legales sólo son importantes para el desarrollo una vez que se ha controlado por otros factores tales como educación y salud entre otros.

El uso de este tipo de variables como instrumentos ya ha sido aplicado para determinar el efecto del sistema bancario en el crecimiento por Levine, Loayza y Beck (1998). La novedad de este artículo es que también se considera el mercado de valores, sobre el cual, como se encontró en la sección anterior, la regulación tiene un impacto más importante.

En el Cuadro 14 se presentan las estimaciones de la tasa de crecimiento de largo plazo obtenidas utilizando el método de mínimos cuadrados en dos etapas. En este análisis, como 
es usual en la literatura de crecimiento, se considera que cualquier ajuste de largo plazo se da en un período de diez años. Además de este supuesto, la metodología utilizada tiene la limitación de que no permite determinar la dinámica del ajuste ni el tiempo que éste tarda en darse.
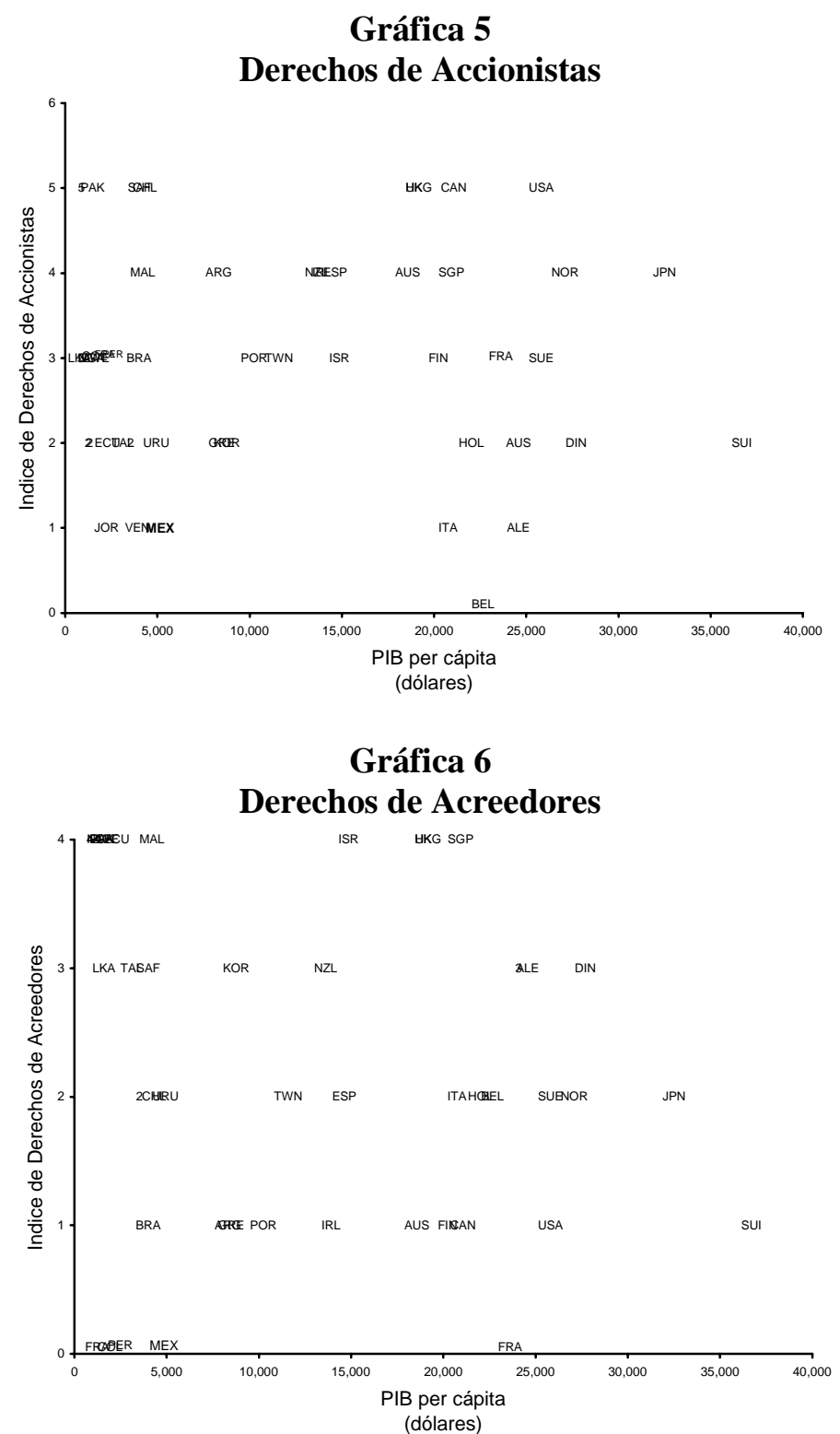

Los instrumentos para las variables del mercado de valores son el índice de protección Iantidir2, la variable de un voto por acción, estándares contables y dividendos obligatorios. Para el caso del endeudamiento sólo se toma el índice Icredit3. Al incluir únicamente las variables del desarrollo del mercado de valores (primeras tres columnas), además de las variables de control, todas son significativas y tienen el signo esperado. Un aumento de 
$10 \%$ del PIB en la capitalización de mercado total o en manos de accionistas minoritarios implica un aumento en la tasa de crecimiento de largo plazo de 0.2 puntos porcentuales. Las especificaciones que contienen estas variables son las que logran el mejor poder explicativo. El crédito bancario al sector privado también resulta significativo, aunque al tomar el modelo en su conjunto no tiene un alto poder explicativo (columna 4), lo cual se debe en parte a que el índice Icredit3 no es tan buen instrumento como los usados para el mercado de valores. Un aumento del crédito bancario de $10 \%$ del PIB llevaría a una tasa de crecimiento mayor en 0.6 puntos porcentuales. El endeudamiento total no resulta significativo posiblemente debido a la calidad del instrumento utilizado o, tal vez más importante, a que esta variable incluye créditos otorgados por el gobierno. Al respecto King y Levine (1993) explican que los bancos privados parecen ser más eficientes en el manejo de riesgos y en general en proveer servicios financieros que el gobierno. De modo que es de esperarse que el endeudamiento total tenga un efecto menos importante en el crecimiento que el crédito bancario. A su vez este indicador conlleva algunos problemas debido a que en muchos países el gobierno también interviene en el otorgamiento de crédito a través de la banca privada.

Al combinar las variables del mercado de valores y crediticio la magnitud de los coeficientes se vuelve mucho menor y en algunos casos pierde la significancia. Esto puede indicar que ambos mercados son sustitutos más que complementos. Para financiar los proyectos rentables basta tener un intermediario financiero que funcione de manera eficiente para contribuir al crecimiento macroeconómico. Sin embargo, los efectos distributivos de ambos mercados pueden ser importantes. En general, el mercado de crédito suele ser más accesible a empresas pequeñas que el acceso al mercado de capitales, ya que para este último se requieren altos costos de entrada.

En la columna 7 se presentan los resultados obtenidos al considerar el tamaño del mercado de crédito bancario y el del mercado de capitales como sustitutos perfectos, de manera que la suma del nivel de capitalización más el crédito bancario represente el tamaño del mercado financiero. En este caso el efecto es significativo. 


\section{Cuadro 14}

Efecto del Desarrollo de los Mercados Financieros sobre el Crecimiento Económico

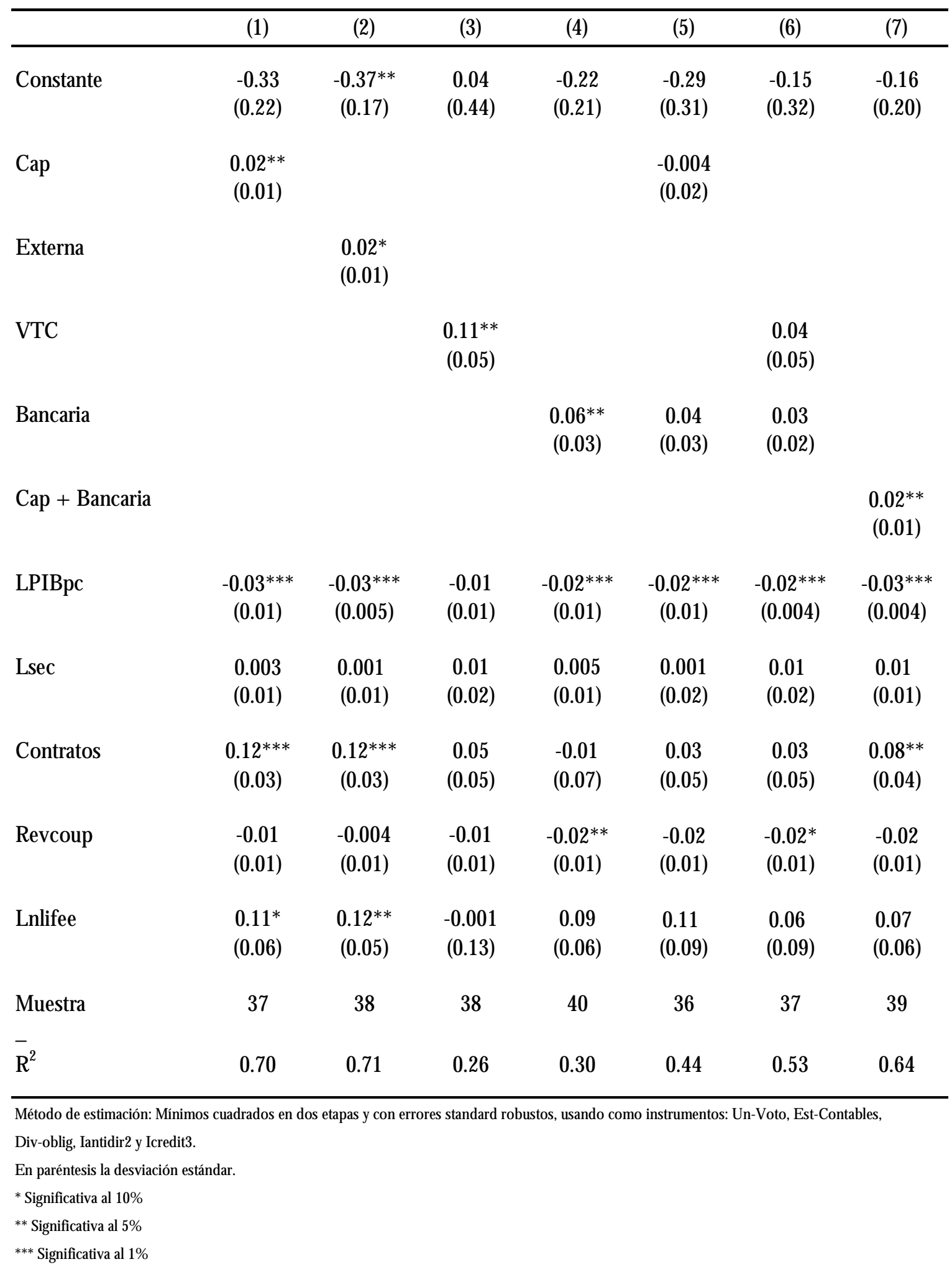


Los resultados encontrados implican que:

- Un aumento en la capitalización del mercado de valores de 50\% del PIB, el cual se alcanzaría de acuerdo al modelo al incluir las regulaciones propuestas, podría aumentar la tasa de crecimiento anual de largo plazo hasta en un punto porcentual.

- Un aumento en el crédito bancario de $25 \%$ del PIB, el cual se alcanzaría de acuerdo al modelo al incluir las regulaciones propuestas, implicaría un aumento en la tasa de crecimiento anual de largo plazo de hasta 1.5 puntos porcentuales.

Tal como se mencionó anteriormente la metodología utilizada no permite determinar el período que tarda en completarse el efecto encontrado, pero es de esperarse que éste no se observe de inmediato.

\section{5 ¿Afecta la Regulación al Financiamiento de las Empresas Grandes?}

Se ha encontrado en este trabajo que la regulación tiene un impacto importante en el desarrollo de los mercados financieros y que éste a su vez tiene un efecto positivo sobre el crecimiento económico. Sin embrago, es de esperarse que el efecto no sea el mismo para las empresas grandes que para las pequeñas. Actualmente se ve que aun en los países con mercados de valores poco desarrollados las grandes empresas logran colocar una gran parte de su capital entre accionistas minoritarios y alcanzar niveles de endeudamiento relativamente altos. Esto puede responder a dos factores. En primer lugar, la reputación creada por estas empresas resulta ser una medida alternativa para resolver problemas de información asimétrica. Pero posiblemente más importante es el hecho de que sólo estas empresas pueden colocar en los mercados externos ya que incluso para las empresas medianas resulta muy costoso. Al colocar en los mercados externos, estas empresas tienen que sujetarse a ciertas normas de modo que enfrentan ciertas medidas de protección a los accionistas minoritarios.

A continuación se analizará formalmente si el financiamiento externo de las empresas grandes se ve limitado por los aspectos regulatorios examinados. Con este propósito se utilizan dos medidas alternativas como indicadores del nivel de endeudamiento de las empresas grandes. La mediana del endeudamiento como proporción de las ventas y como 
proporción del flujo de caja y dos indicadores de la emisión de capital de empresas grandes: el valor de mercado de las acciones en manos de externos como proporción del flujo de caja y como proporción de las ventas.

En el Cuadro 15 se presentan los resultados del efecto de las medidas de protección en el endeudamiento de las empresas grandes. Contrario a lo esperado, se obtiene que también las grandes empresas se ven afectadas por deficiencias en la regulación. Resulta difícil comparar la magnitud del efecto con la del promedio por país, ya que las variables de escala utilizadas en ambos casos no son equivalentes. Al igual que en el caso del endeudamiento total del sector privado la medida más importante resulta ser la de no permitir la permanencia del administrador cuando se lleva a cabo una reorganización. Sin embargo, en esta situación las medidas tomadas individualmente tienen un mayor poder explicativo que para el endeudamiento total, mientras que los índices tienen un bajo poder explicativo. En su conjunto las medidas de protección explican el 15\% de la variación (ajustando por el número de variables explicativas) de las diferencias en el endeudamiento de las empresas grandes como proporción del flujo de caja y 7\% de la variación cuando este endeudamiento se normaliza con las ventas totales. En contraste, esta proporción es de 2\% para el caso del crédito bancario y de $1 \%$ para el endeudamiento total. 


\section{Cuadro 15}

Efecto de la Protección a Acreedores sobre el Endeudamiento de las Empresas Grandes

\begin{tabular}{|c|c|c|c|c|c|c|c|c|}
\hline & \multicolumn{4}{|c|}{ D euda/ Flujo } & \multicolumn{4}{|c|}{ D euda/ Vtas } \\
\hline & (1) & (2) & (3) & (4) & (5) & (6) & (7) & (8) \\
\hline Constante & $\begin{array}{c}1.54^{* * *} \\
-0.52\end{array}$ & $\begin{array}{r}0.19 \\
-1.05\end{array}$ & $\begin{array}{c}0.99 \\
-1.12\end{array}$ & $\begin{array}{c}0.45 \\
-1.09\end{array}$ & $\begin{array}{c}0.28 * * * \\
-0.06\end{array}$ & $\begin{array}{c}0.44^{* * *} \\
-0.12\end{array}$ & $\begin{array}{c}0.45^{* * *} \\
-0.12\end{array}$ & $\begin{array}{c}0.42^{* * *} \\
-0.12\end{array}$ \\
\hline Garantías & $\begin{array}{l}-0.49 \\
-0.46\end{array}$ & $\begin{array}{l}-0.58 \\
-1.26\end{array}$ & & & $\begin{array}{l}-0.003 \\
-0.05\end{array}$ & $\begin{array}{c}0.01 \\
-0.05\end{array}$ & & \\
\hline Prelación & $\begin{array}{c}0.66 \\
-0.52\end{array}$ & $\begin{array}{c}0.45 \\
-0.53\end{array}$ & & & $\begin{array}{l}-0.01 \\
-0.06\end{array}$ & $\begin{array}{c}0.02 \\
-0.06\end{array}$ & & \\
\hline Reorgan & $\begin{array}{l}-0.62 \\
-0.41\end{array}$ & $\begin{array}{l}-0.60 \\
-0.41\end{array}$ & & & $\begin{array}{l}-0.08^{*} \\
-0.05\end{array}$ & $\begin{array}{c}-0.09 * \\
-0.04\end{array}$ & & \\
\hline Admon & $\begin{array}{c}1.36^{* * *} \\
-0.47\end{array}$ & $\begin{array}{c}1.52^{* * *} \\
-0.48\end{array}$ & & & $\begin{array}{l}0.09 * \\
-0.05\end{array}$ & $\begin{array}{l}0.07 \\
-0.05\end{array}$ & & \\
\hline Reserva & $\begin{array}{c}1.64 \\
-1.05\end{array}$ & $\begin{array}{c}1.54 \\
-1.04\end{array}$ & & & $\begin{array}{c}0.11 \\
-0.11\end{array}$ & $\begin{array}{c}0.12 \\
-0.11\end{array}$ & & \\
\hline Contratos & & $\begin{array}{c}1.85 \\
-1.26\end{array}$ & $\begin{array}{c}1.37 \\
-1.29\end{array}$ & $\begin{array}{c}1.37 \\
-1.24\end{array}$ & & $\begin{array}{l}-0.22 \\
-0.14\end{array}$ & $\begin{array}{l}-0.21 \\
-0.14\end{array}$ & $\begin{array}{l}-0.21 \\
-0.13\end{array}$ \\
\hline Icred1 & & & $\begin{array}{c}0.06 \\
-0.16\end{array}$ & & & & $\begin{array}{l}-0.005 \\
-0.02\end{array}$ & \\
\hline Icred3 & & & & $\begin{array}{l}0.56^{*} \\
-0.32\end{array}$ & & & & $\begin{array}{c}0.02 \\
-0.03\end{array}$ \\
\hline Muestra & 37 & 37 & 37 & 37 & 38 & 38 & 38 & 38 \\
\hline$\overline{\mathrm{R}}^{2}$ & 0.15 & 0.18 & -0.02 & 0.06 & 0.07 & 0.11 & 0.01 & 0.02 \\
\hline
\end{tabular}

La variable dependiente "D euda-Flujo" se refiere a la deuda total de las empresas grandes, como proporción del flujo de caja.

La variable dependiente "D euda-V tas" se refiere a la deuda total de las empresas grandes, como proporción de las ventas.

En paréntesis la desviación estándar.

* Significativa at $10 \%$

** Significativa al $5 \%$

*** Significativa at $1 \%$

Para poner en perspectiva la importancia de las medidas de protección de los derechos de los acreedores en las empresas grandes, se puede decir que de impedirse la permanencia del administrador durante una reorganización, el endeudamiento como proporción del flujo de caja de las empresas grandes mexicanas se podría casi duplicar, mientras que el impacto en el endeudamiento bancario del sector privado como proporción del PIB sería ligeramente mayor que $50 \%$ y en el endeudamiento total ligeramente menor que 50\%. Es importante 
resaltar que el alto impacto de la medida mencionada se debe a que en la mayoría de los países en los que no se impide la permanencia no se cuenta con medidas que limiten las acciones del administrador, de modo que se evite que éste "saquee" los activos de la empresa. Puede ser que teniendo una vigilancia adecuada del administrador se pueda conservar el conocimiento que éste tiene de la empresa para garantizar el óptimo desempeño, sin incurrir en el peligro de que se extraigan recursos de ésta.

Cuando se normaliza el endeudamiento de las empresas grandes con las ventas, la importancia de las medidas no es tan fuerte e incluso pierden la significancia en todas las especificaciones excepto en una, cuando se toma el flujo de caja.

Como se aprecia en el Cuadro 16, también la emisión por empresas grandes se ve afectada por el entorno legal en cuanto a la protección a accionistas minoritarios. Este resultado se observa cuando el valor de capitalización se normaliza con el flujo de efectivo (primeras tres columnas), pero es casi insignificante al utilizar las ventas (últimas tres columnas). El efecto de las diferentes medidas resulta muy similar al caso de todo el mercado. La restricción de un voto por acción tiene un impacto importante y significativo, la obligación de reparto de dividendos tiene un efecto negativo y significativo en muchos casos. Además, el índice Iantidir1 es significativo. 


\section{Cuadro 16}

Efecto de la Protección a Accionistas Minoritarios sobre el Financiamiento vía Emisión de Capital de Empresas Grandes

\begin{tabular}{|c|c|c|c|c|c|c|}
\hline & \multicolumn{3}{|c|}{ Cap/ Flujo } & \multicolumn{3}{|c|}{ Cap/ Vtas } \\
\hline & (1) & (2) & (3) & (4) & (5) & (6) \\
\hline Constante & $\begin{array}{c}0.33 \\
(3.93)\end{array}$ & $\begin{array}{c}3.60 \\
(3.70)\end{array}$ & $\begin{array}{c}4.45 \\
(3.96)\end{array}$ & $\begin{array}{c}-0.04 \\
(0.70)\end{array}$ & $\begin{array}{c}0.71 \\
(0.60)\end{array}$ & $\begin{array}{c}0.74 \\
(0.63)\end{array}$ \\
\hline Div-Oblig & $\begin{array}{l}-8.34 \\
(5.46)\end{array}$ & $\begin{array}{c}-10.27 * \\
(5.92)\end{array}$ & $\begin{array}{c}-10.61 * \\
(6.31)\end{array}$ & $\begin{array}{c}-0.28 \\
(0.92)\end{array}$ & $\begin{array}{c}-0.84 \\
(0.91)\end{array}$ & $\begin{array}{c}-0.78 \\
(0.94)\end{array}$ \\
\hline Un-Voto & $\begin{array}{c}4.33 * * \\
(1.70)\end{array}$ & $\begin{array}{c}4.27 * * \\
(1.64)\end{array}$ & $\begin{array}{c}4.51 * * \\
(1.80)\end{array}$ & $\begin{array}{c}0.14 \\
(0.28)\end{array}$ & $\begin{array}{c}0.27 \\
(0.23)\end{array}$ & $\begin{array}{c}0.25 \\
(0.25)\end{array}$ \\
\hline Est-Contables & $\begin{array}{l}0.005 \\
(0.05)\end{array}$ & $\begin{array}{l}-0.03 \\
(0.06)\end{array}$ & $\begin{array}{c}-0.003 \\
(0.06)\end{array}$ & $\begin{array}{c}0.01 \\
(0.01)\end{array}$ & $\begin{array}{c}0.01 \\
(0.01)\end{array}$ & $\begin{array}{c}0.01 \\
(0.01)\end{array}$ \\
\hline Llamado & $\begin{array}{c}0.98 \\
(1.40)\end{array}$ & & & $\begin{array}{c}0.07 \\
(0.26)\end{array}$ & & \\
\hline Correo & $\begin{array}{l}0.33 \\
(1.25)\end{array}$ & & & $\begin{array}{c}-0.12 \\
(0.23)\end{array}$ & & \\
\hline Voto-Acum & $\begin{array}{c}3.23 * * * \\
(1.09)\end{array}$ & & & $\begin{array}{c}0.45^{* *} \\
(0.19)\end{array}$ & & \\
\hline Min-Oprim & $\begin{array}{c}0.75 \\
(1.27)\end{array}$ & & & $\begin{array}{c}0.16 \\
(0.23)\end{array}$ & & \\
\hline Der-comp & $\begin{array}{c}-0.81 \\
(0.89)\end{array}$ & & & $\begin{array}{c}0.01 \\
(0.15)\end{array}$ & & \\
\hline No-Bloqueo & $\begin{array}{c}-0.91 \\
(1.02)\end{array}$ & & & $\begin{array}{c}0.04 \\
(0.17)\end{array}$ & & \\
\hline Contratos & $\begin{array}{c}3.04 \\
(3.77)\end{array}$ & $\begin{array}{c}0.99 \\
(3.80)\end{array}$ & $\begin{array}{l}-0.25 \\
(4.22)\end{array}$ & $\begin{array}{c}-0.64 \\
(0.69)\end{array}$ & $\begin{array}{l}-1.21^{*} \\
(0.63)\end{array}$ & $\begin{array}{c}-1.22^{*} \\
(0.68)\end{array}$ \\
\hline Iantidir1 & & $\begin{array}{l}0.67 * \\
(0.37)\end{array}$ & & & $\begin{array}{l}0.10^{1} \\
(0.06)\end{array}$ & \\
\hline Iantidir2 & & & $\begin{array}{c}0.23 \\
(0.69)\end{array}$ & & & $\begin{array}{l}0.10 \\
(0.11)\end{array}$ \\
\hline Muestra & 34 & 34 & 34 & 35 & 35 & 35 \\
\hline $\mathrm{R}^{2}$ & 0.41 & 0.18 & 0.09 & 0.24 & 0.16 & 0.11 \\
\hline
\end{tabular}

La variable dependiente "Cap-Flujo" se refiere a la capitalización de accionistas minoritarios, como proporción del flujo de caja.

La variable dependiente "Cap-Vtas" se refiere a la capitalización de accionistas minoritarios, como proporción de las ventas.

En paréntesis la desviación estándar.

${ }^{1}$ Significativa al $12 \%, *$ Significativa al $10 \%,{ }^{* *}$ Significativa al $5 \%, * * *$ Significativa al $1 \%$.

\section{6 ¿Afecta el Marco Legal al Financiamiento Externo?}

Un aspecto importante a resaltar es el del papel que juega la protección de los derechos de propiedad en los flujos de capitales externos y el efecto que éstos tienen sobre el 
crecimiento económico. En la literatura económica se considera a la apertura al flujo de capitales externos como una solución a la carencia de un sistema financiero desarrollado o eficiente. Con base en el análisis precedente, si el rezago de este sector es atribuible a un marco legal inadecuado entonces una apertura sólo resolverá el problema si se incorporan cláusulas que permitan utilizar un marco regulatorio y un tribunal de justicia de mejor calidad que el vigente en el país.

Para ilustrar la importancia del marco legal o bien de la calidad del gobierno corporativo de las empresas para atraer inversión extranjera, se tiene el reporte del BID sobre México de septiembre de 1999, donde se menciona la importancia de un nivel adecuado en cuanto a los estándares de gobierno corporativo. TIAA-CREF uno de los inversionistas institucionales más grandes de los E.U.A., ha establecido que no invertirá en papel emitido por empresas con bajos estándares en este aspecto. Entre los requisitos que menciona se encuentran los siguientes:

1. El Consejo de Administración de la empresa deberá contar con una mayoría de directores independientes.

2. El Consejo de Administración de la empresa deberá contar con el apoyo de los accionistas para llevar a cabo cualquier acción que altere las relaciones fundamentales entre el consejo y los accionistas.

3. Las empresas deben basar las compensaciones de los ejecutivos de acuerdo a un esquema de desempeño y deberán proveer información completa y clara de los arreglos de compensaciones.

Este tipo de medidas se incluyen en regulaciones adecuadas de gobierno corporativo, tal como se vio en las secciones anteriores.

A continuación se desarrolla un análisis empírico para determinar si en efecto estas regulaciones afectan los flujos de capitales externos. La variable más adecuada para este propósito resulta ser la inversión extranjera en cartera. Desgraciadamente la serie disponible incluye inversiones en ADRs, instrumentos que se sujetan a ciertos aspectos de la regulación de los E.U.A. y, por ende, no se ven afectados en la misma medida que las acciones comerciadas en bolsas locales por la calidad de la regulación en su país de origen. A pesar de este problema se realizó el análisis, ya que de obtenerse que a pesar de la 
inclusión de ADRs los coeficientes de las variables de protección a accionistas minoritarios son significativos y del signo esperado, se corroboraría la hipótesis. Esto no sucede por lo que no es posible aceptar la hipótesis propuesta, aunque tampoco rechazarla debido a la deficiencia en la variable utilizada.

Alternativamente se utilizó la Inversión Extranjera Directa (IED), la cual tiene el problema de que la mayor parte de ésta representa a inversionistas que mantienen el control. Lo anterior implica que dichos inversionistas no se ven afectados directamente por la ausencia de protección a los accionistas minoritarios. Sin embargo, este tipo de regulación puede dar seguridad al inversionista cuando comparte la propiedad con los administradores de la empresa, al servirle como un mecanismo de control adicional.

En el Cuadro 17 se presentan las estimaciones de la IED incluyendo como variables explicativas a las diferentes medidas e índices de protección a accionistas minoritarios, de protección a acreedores y de seguimiento de la legalidad. La significancia de estas variables resulta mucho menor que la obtenida en las regresiones del mercado de valores. La obligatoriedad de mantener un voto por acción resulta significativa en casi todas las especificaciones, los estándares contables y el índice de protección tienen el signo esperado, pero no siempre son significativos. Es importante enfatizar la caída en el poder explicativo del cumplimiento de la legalidad. En este caso ninguna de las proxies resulta significativa, lo cual es sorprendente especialmente en comparación con el poder explicativo que tenían en las estimaciones presentadas a lo largo de este trabajo.

La caída en el poder explicativo del cumplimiento de la legalidad puede deberse a que algunos países cuentan con tratados internacionales que otorgan cierta protección a los inversionistas extranjeros. Por ejemplo, en México a raíz de la entrada en vigor del Tratado de Libre Comercio de América del Norte (TLCAN) se ha resuelto parcialmente el problema de deficiencias legales e institucionales. En el capítulo 11 de este tratado se establecen los derechos que se otorgan a los inversionistas extranjeros pertenecientes a los países que forman parte del tratado. Una concesión importante es que se permite a las personas físicas o morales de los E.U.A. y de Canadá que realicen inversiones en México ${ }^{11}$ resolver las

\footnotetext{
${ }^{11}$ Sobra decir que lo mismo aplica para los tres países.
} 
controversias con base en el derecho y a tribunales internacionales. De manera que en este sentido algunas de las deficiencias en instituciones locales y en ciertas regulaciones no afectan a los inversionistas de países miembros del TLCAN.

\section{Cuadro 17}

Efecto de la Protección a Accionistas Minoritarios sobre la Inversión Extranjera Directa

\begin{tabular}{|c|c|c|c|c|c|c|}
\hline & (1) & (2) & (3) & (4) & (5) & (6) \\
\hline Constante & $\begin{array}{l}-0.43 \\
(0.77)\end{array}$ & $\begin{array}{l}-1.06 \\
(0.79)\end{array}$ & $\begin{array}{l}-1.48 \\
(1.08)\end{array}$ & $\begin{array}{c}-1.04 \\
(1.21)\end{array}$ & $\begin{array}{c}0.97 \\
(2.07)\end{array}$ & $\begin{array}{l}-1.45 \\
(0.93)\end{array}$ \\
\hline Div-O blig & $\begin{array}{c}-0.36 \\
(1.57)\end{array}$ & $\begin{array}{c}-0.53 \\
(1.50)\end{array}$ & $\begin{array}{c}-0.44 \\
(1.53)\end{array}$ & $\begin{array}{l}-1.42 \\
(2.06)\end{array}$ & $\begin{array}{c}-0.49 \\
(1.94)\end{array}$ & $\begin{array}{c}-0.21 \\
(1.58)\end{array}$ \\
\hline Un-Voto & $\begin{array}{c}1.05^{* *} \\
(0.51)\end{array}$ & $\begin{array}{c}0.91^{* *} \\
(0.50)\end{array}$ & $\begin{array}{l}0.88 * \\
(0.50)\end{array}$ & $\begin{array}{l}1.21 * \\
(0.64)\end{array}$ & $\begin{array}{c}0.81 \\
(0.59)\end{array}$ & $\begin{array}{l}0.98 * \\
(0.53)\end{array}$ \\
\hline Cum-Leg & $\begin{array}{l}1.14 \\
(0.81)\end{array}$ & $\begin{array}{l}1.38 * \\
(0.78)\end{array}$ & & $\begin{array}{c}0.88 \\
(1.18)\end{array}$ & $\begin{array}{l}3.11 * \\
(1.86)\end{array}$ & $\begin{array}{l}1.51 * \\
(0.81)\end{array}$ \\
\hline Est-Contables & & & & $\begin{array}{c}0.01 \\
(0.02)\end{array}$ & & \\
\hline Iantidir1 & $\begin{array}{c}0.18 \\
(0.17)\end{array}$ & & & & & \\
\hline Iantidir2 & & $\begin{array}{c}0.58 * * \\
(0.27)\end{array}$ & $\begin{array}{c}0.57 * * \\
(0.28)\end{array}$ & $\begin{array}{l}0.61 * \\
(0.37)\end{array}$ & & $\begin{array}{l}0.48^{1} \\
(0.29)\end{array}$ \\
\hline Icred1 & & & & & & $\begin{array}{c}0.20 \\
(0.16)\end{array}$ \\
\hline Contratos & & & $\begin{array}{c}1.82 \\
(1.16)\end{array}$ & & & \\
\hline LPIBpc & & & & & $\begin{array}{c}-0.40 \\
(0.36)\end{array}$ & \\
\hline Muestra & 46 & 46 & 46 & 38 & 39 & 44 \\
\hline $\mathrm{R}^{2}$ & 0.07 & 0.14 & 0.12 & 0.12 & 0.14 & 0.14 \\
\hline
\end{tabular}

La variable dependiente se refiere a la Inversión Extranjera Directa.

En paréntesis la desviación estándar.

1 Significativa al 11\%

* Significativa al 10\%

** Significativa al 5\%

*** Significativa al 1\% 
A partir de 1994 México ha firmado una serie de acuerdos internacionales ${ }^{12}$ que otorgan estos derechos a otros países como Alemania, Argentina, Austria, Dinamarca, España, Finlandia, Holanda, Italia, Portugal, Suiza, Unión Belgo-Luxemburguesa e Uruguay. Además han entrado en vigor otros tratados de libre comercio que incluyen cláusulas equivalentes para la resolución de conflictos que afecten a inversionistas. En el Cuadro 18 se muestran todos los países con los que se tiene algún acuerdo de este tipo así como la fecha de entrada en vigor.

\section{C uadro 18}

\begin{tabular}{|c|c|c|}
\hline País & Tratado & Fecha de entrada \\
\hline Estados Unidos & TLC de A mérica del Norte* & Vigor: Enero de 1994 \\
\hline Canadá & TLC de A mérica del Norte* & Vigor: Enero de 1994 \\
\hline Suiza & APPRIS* & $\begin{array}{l}\text { Firma: Julio de } 1995 \\
\text { A probado: N oviembre de } 1995\end{array}$ \\
\hline España & APPRIS* & $\begin{array}{l}\text { Firma: Junio de } 1995 \\
\text { A probado: N oviembre de } 1995\end{array}$ \\
\hline A rgentina & APPRIS * & Firma: N oviembre de 1996 \\
\hline Chile & TLC * & $\begin{array}{l}\text { Firma: A bril de } 1998 \\
\text { A probado: N oviembre de } 1998 \\
\text { D ecreto: Julio de } 1999\end{array}$ \\
\hline Colombia y Venezuela & $\begin{array}{l}\text { TLC del Grupo de los Tres* } \\
\text { (Colombia, Venezuela y México) }\end{array}$ & $\begin{array}{l}\text { Firma: Junio de } 1994 \\
\text { Vigor: Enero de } 1995\end{array}$ \\
\hline Nicaragua & TLC * & $\begin{array}{l}\text { Firma: Diciembre de } 1997 \\
\text { A probado: A bril de } 1998 \\
\text { D ecreto: Julio de } 1998\end{array}$ \\
\hline $\begin{array}{l}\text { Guatemala, H onduras } \\
\text { y El Salvador }\end{array}$ & $\begin{array}{l}\text { TLCT N M (T LC, Triángulo del N orte) * } \\
\text { (Guatemala, H onduras, El Salvador y } \\
\text { México) }\end{array}$ & Vigor: Enero de 2001 \\
\hline Unión Europea & TLC ** & $\begin{array}{l}\text { D ecreto: Junio de } 2000 \\
\text { Vigor: Julio de } 2000\end{array}$ \\
\hline
\end{tabular}

\footnotetext{
${ }^{12}$ Estos acuerdos se denominan APPRI (Acuerdos para la Promoción y Protección Recíproca de Inversiones).
} 
Estos tratados podrían explicar en parte el incremento en la IED en México, la cual pasó de un promedio de $1.2 \%$ del PIB para el período de 1990 a 1994 a un nivel promedio de $2.9 \%$ del PIB para el periodo de 1995 a 1999.

Para medir la importancia de estos tratados, al otorgarse la garantía de resolver conflictos legales con la participación de jueces externos, en los flujos de inversión se estimaron varias especificaciones de los determinantes de la IED a México por país de origen. Los datos utilizados provienen de la OECD para el período de 1980 a 1997 y de SECOFI para 1998 y 1999. En las regresiones se excluye 1998 debido a que la cifra de ese año no es comparable con las publicadas por la OECD. La primera fuente incluye 63 países y la segunda 33. En las regresiones se tomaron los 34 países más importantes, de los cuales nueve no aparecen en los datos de SECOFI.

Para medir el impacto de los tratados se incluye una variable binaria para cada tratado, tomando el valor de uno a partir del año en que éste entra en vigor. Como controles se incluyen efectos fijos por país para captar cualquier factor que sea específico, tal como tamaño, tasas de crecimiento, niveles de ahorro o desahorro neto. Además, se incluyen variables binarias por año, controlando por eventos internacionales tales como crisis globales y eventos que afectan a todos los países como son las fluctuaciones en los términos de intercambio.

En el Cuadro 19 se muestran los resultados. En la primera columna aparecen las observaciones que se tienen para el período con tratado de cada país. Ello, con el propósito de mostrar que al ser muy recientes estos acuerdos y al no tener disponibles algunas observaciones se cuenta con pocos grados de libertad para el análisis que se desea realizar. Este problema se vuelve más importante si se considera que países como Suiza invierten flujos tan pequeños que resultan sumamente volátiles por la naturaleza de indivisibilidad de la inversión. Dicho país representó el 0.8\% de la IED en México durante el período 19941999 invirtiendo montos anuales de entre 18 y 200 millones de dólares.

La inversión proveniente de Canadá, medida en términos del PIB, es la única que se ve afectada de manera positiva y significativa por el tratado bajo las tres especificaciones. El impacto del tratado en la inversión proveniente de este país es de 44\% al tomar la IED como proporción del PIB y de 50\% al tomar el logaritmo. Para el caso de los E.U.A, el 
impacto es significativo al tomar niveles y logaritmos, pero no así al tomar a la IED como proporción del PIB. Esto último se debe a que si bien en los últimos años la inversión proveniente de ese país ha sido muy vigorosa, también lo ha sido su crecimiento económico. El impacto al tomarse logaritmos es de $68 \%$ y al tomarse proporciones del PIB es de $33 \%$. Para el resto de los países no se obtiene un efecto significativo, salvo para Suiza que resulta incluso negativo y significativo. Posiblemente esto se deba a que estos tratados son muy recientes y sólo se cuenta con un período muy corto desde su entrada en vigor, además de no disponerse de datos de IED comparables para 1998.

\section{Cuadro 19}

E fecto de la Protección a Inversionistas sobre la Inversión Extranjera Directa en México

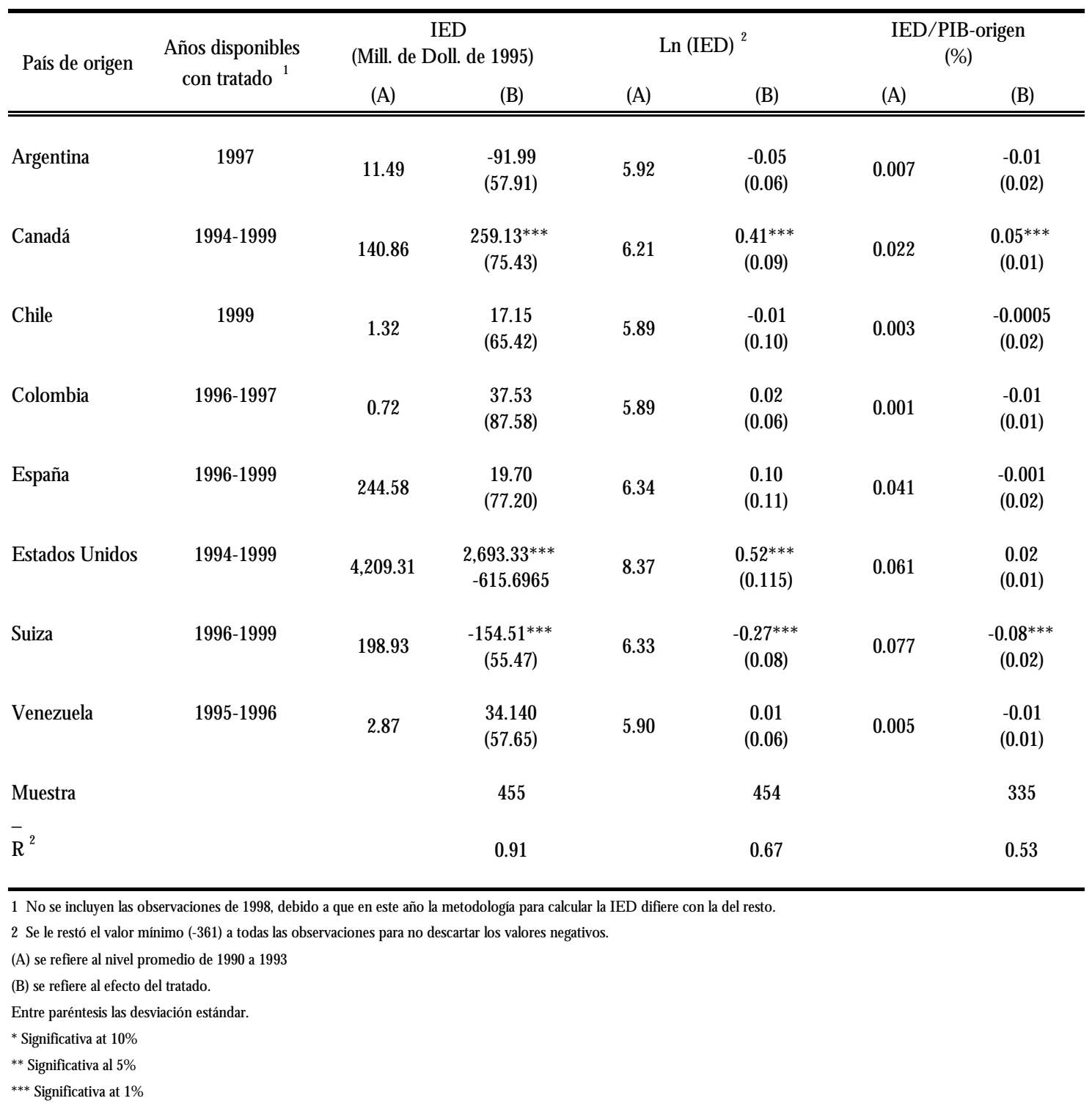


Estimando una regresión similar pero considerando el efecto del tratado común a todos los países, se obtiene que al tomarse logaritmos éste es de 17\% y significativo, y no significativo al tomarse proporciones del PIB.

Sería interesante analizar este aspecto con más detalle, especialmente en lo que se refiere a una derivación formal de la especificación a ser estimada. Con base en los resultados obtenidos, las conclusiones de la importancia de estos tratados dependen en gran medida de la forma funcional de la IED que se adopte.

Para concluir la sección referente a flujos de capital se consideró el efecto de éstos sobre el crecimiento económico. Con este propósito se emplearon diversas especificaciones, para captar las diferentes maneras en las que puede tener un impacto esta variable. Incluso se consideró el hecho de que la IED puede ser importante únicamente cuando los mercados financieros nacionales no son eficientes. Alternativamente, se consideró que el desarrollo de los mercados de intermediación nacionales tendrá un efecto sobre el crecimiento únicamente cuando no se cuente con la posibilidad de recurrir al financiamiento externo.

En la mayoría de las especificaciones realizadas no se encontró que la IED afectara de manera significativa al crecimiento económico. Esto puede deberse a la dificultad en modelar la interacción entre el financiamiento interno y el externo como determinantes del crecimiento.

\section{La Protección de Derechos en México}

En la sección de análisis de datos se discutió el rezago en México en cuanto al marco legal, encontrándose que el país no cuenta con ninguna de las medidas de protección a accionistas minoritarios y que hasta 1999 tampoco contaba con ninguna de las medidas de protección a acreedores garantizados. Esta deficiencia lleva a analizar de manera más detallada la legislación mexicana.

En lo concerniente a la protección a acreedores, México contaba hasta abril de 2000 con la Ley de Quiebras y Suspensión de Pagos (LQSP) que databa de 1943. A partir de entonces entró en vigor la Miscelánea de Garantías de Crédito (MGC) que reforma diversas disposiciones legales para crear mejores condiciones para el otorgamiento de créditos y la 
Ley de Concursos Mercantiles (LCM) que abroga a la LQSP, solucionando algunos de los problemas aquí mencionados. En dicha ley se mejora la protección a los acreedores garantizados. De acuerdo a las cuatro medidas consideradas en este trabajo sobre la protección de los derechos a dichos acreedores, la nueva ley establece lo siguiente:

1. Consentimiento de los acreedores para solicitar la reorganización o, en el caso de México, para entrar al proceso de conciliación (Reorgan).- En la LCM se establece que el comerciante o deudor puede solicitar la entrada al proceso de concurso mercantil y la aprobación de éste no requiere del consentimiento de ninguno de los acreedores.

2. No se quedan automáticamente las garantías (Garantía).- De acuerdo al artículo 65 de la ley mencionada, los activos de la empresa se quedan en ésta durante el proceso de conciliación, el cual puede durar hasta un año. Una vez que concluye este proceso se permite la enajenación del colateral por parte de los acreedores garantizados. Esto contrasta con lo estipulado en otros países, por ejemplo en el Reino Unido, en los que se permite la separación de las garantías en cualquier momento del proceso o en Alemania donde sólo se quedan si consideran que son fundamentales para la operación y en este caso se cubren los intereses de los activos que se mantienen para continuar la operación o para optimizar el valor de liquidación. En México también se pagan intereses, pero se le impone un limite al monto de éstos.

3. Prelación de los acreedores garantizados (Prelación).- En relación a la prelación de dichos acreedores (Art. 217 y 224), se avanzó en relación a lo establecido en la ley de quiebras anterior. Estos acreedores pueden enajenar las garantías una vez que se cubrieron ciertas obligaciones laborales y los gastos administrativos del proceso. De manera que aún no alcanzan la prioridad que se les da en países como en Alemania y el Reino Unido, donde se limitan considerablemente los gastos administrativos que preceden a los mencionados acreedores a aquéllos que se incurren para mantener el valor de las garantías. Además, en estos países los acreedores garantizados preceden a las obligaciones laborales.

4. No se permite que el deudor mantenga la administración durante la reorganización o conciliación (Admon).- De acuerdo al artículo 74 de la LCM no se impide la permanencia de la administración durante la reorganización. Aunque se incluyen ciertas 
medidas para evitar acciones a favor del administrador y en perjuicio de los acreedores. Por un lado, se requiere de la aprobación de acreedores para cierto tipo de acciones y, por otro, se incluyen medidas relativas a las responsabilidades del síndico. Además, en el artículo 81 se establece que el conciliador podrá solicitar la remoción del comerciante.

En términos muy estrictos la LCM no incluye ninguna de las medidas de protección citadas. Sin embargo, bajo una interpretación más flexible podría considerarse la inclusión de la no permanencia de la administración. Es importante enfatizar que tal como mencionan LLSV 1998 existe un trade-off entre una regulación con mayor discrecionalidad y una más rígida. La primera puede resultar muy eficiente si se tienen instituciones muy sólidas que logran dar protección a los acreedores sin la necesidad de llevar a la quiebra a empresas, cuando es socialmente óptimo que continúen operando. Con base en esto es posible que la flexibilidad que permite la LCM sea óptima.

También es importante destacar que la MGC sí otorga una gran protección al acreedor en diversos aspectos. Por ejemplo, esta ley facilita la adjudicación de la garantía por parte del acreedor cuando el deudor no cubra sus obligaciones, la cual puede darse en un plazo aproximado de seis meses. De tal manera que si para entrar en concurso mercantil se requiere de un período de incumplimiento similar, el acreedor podrá hacer uso del derecho que le otorga la MGC para evitar una mayor pérdida. Sin embargo, cabe destacar que lo óptimo desde el punto de vista social resulta ser una mejor protección bajo la LCM. De no ser así, si la garantía es fundamental para la operación de la empresa no se podrá llevar a cabo la reestructura aun cuando ésta fuera deseable socialmente.

Otro punto que se contempla en la nueva ley es el de coordinación. En general en los sistemas legales con tradición civil resulta muy difícil la coordinación entre los acreedores. En virtud de este aspecto, la LCM busca fomentar y facilitar esta cooperación para crear las mismas condiciones para todos los acreedores. Estas medidas logran entre otras cosas que los inversionistas extranjeros cuenten con una protección legal equiparable a la del origen de su capital. 
En esta sección se enfatiza la legislación relativa al gobierno corporativo o de protección a los accionistas minoritarios ${ }^{13}$, la cual tiene más de medio siglo de existencia y ha sido sólo parcialmente revisada desde entonces. Como se mencionó anteriormente una legislación de este tipo es importante para resolver el problema de agencia que surge cuando el control y la propiedad de una empresa no coinciden por completo. Para ello, dicha legislación necesita asegurar un grado mínimo de protección de los intereses de inversionistas externos.

En México, la Ley General de Sociedades Mercantiles de 1934 se ocupa de regular los asuntos relacionados al gobierno corporativo. Esta ley parte del Código Comercial y tiene su origen en el sistema legal francés. En ella se define a la sociedad anónima y se describen los órganos que la deben regir y se cubren aspectos tales como la emisión de acciones, los derechos de propiedad del accionista, las reglas de gobierno del Consejo de Administración, el papel del Comisario, los procedimientos para fusiones y liquidaciones, etc.

Además de esta legislación las empresas que cotizan públicamente en la BMV están regidas por otras regulaciones: la Ley del Mercado de Valores de 1975 y circulares emitidas por la Comisión Nacional Bancaria y de Valores $(C N B V)$. También son importantes en la regulación de gobierno corporativo las reglas que aplican a empresas que cotizan públicamente y que se encuentran en el Reglamento de la Ley de Inversión Extranjera y del Registro Nacional de Inversiones Extranjeras de 1998, el cual contiene provisiones acerca de los límites sobre los derechos de votación de acciones adquiridas por extranjeros.

Analizando un poco más a fondo este marco regulatorio se encuentra que a pesar de que las instituciones básicas necesarias para una defensa efectiva de los derechos de las minorías existen (Consejo de Administración, Asamblea de Accionistas obligatoria y Comisario de la empresa), éste presenta algunas deficiencias que se dividen en cuatro categorías:

1. Falta especificidad en la ley con respecto a la estructura del proceso y de las partes encargadas de la toma de decisiones, abriendo la posibilidad a accionistas que detentan

\footnotetext{
${ }^{13}$ Este análisis se basa en Babatz (1997), donde se encontrará una descripción más completa de la regulación mexicana en este aspecto.
} 
el control de usarlo a su favor y en detrimento de las minorías.- Durante las asambleas de accionistas se toma gran parte de las decisiones más importantes de la empresa, pero la manera como se toman las decisiones deja desprotegidas a las minorías. El Consejo Directivo se encarga de llevar a cabo los acuerdos alcanzados y de nombrar a los administradores que vigilarán la operación diaria de la empresa. El único requisito legal para la composición del consejo es que las minorías que representen 10\% o más de los derechos de voto podrán elegir al menos a un miembro. Sin embargo, no se limita el número de miembros que constituyen el consejo, de manera que no es difícil que los accionistas mayoritarios logren alcanzar la mayoría absoluta de los votos. De ser este el caso, dichos accionistas pueden controlar no sólo las decisiones fundamentales sino además los temas de discusión.

2. Falta de transparencia en los reportes exigidos a las empresas que cotizan en Bolsa.Debido a que el nivel de detalle con el que debían reportarse los gastos era muy vago, y a que no existían estándares para la revelación de inversiones o adquisiciones de la empresa, la regulación en este aspecto se ha ido revisando. La circular 11-11 emitida por la CNBV en 1985 y sus diversas modificaciones ${ }^{14}$ regulan la información económica, contable, jurídica y administrativa que las emisoras deben proporcionar a dicha Comisión, al público inversionistas y a la BMV. Inicialmente estos requisitos eran poco exigentes poniendo en gran desventaja a las minorías al dificultarles la vigilancia efectiva de la empresa. Esto era especialmente patente en dos áreas: el nivel de desagregación requerido de gastos corporativos y los estándares de divulgación concernientes a las inversiones y adquisiciones de empresas en las cuales uno o más de los miembros del Consejo de Administración tienen algún interés. Esta falta de transparencia en los requerimientos de reporte facilita la desviación de recursos en detrimento del accionista minoritario.

Las modificaciones recientes a la Circular mencionada han llevado a un gran avance. De tal suerte que la última modificación exige que las empresas emisoras revelen el grado de adhesión en cada uno de los puntos del Código de mejores prácticas

\footnotetext{
${ }^{14}$ Modificaciones a la Circular 11-11: 11-11 bis2-8.
} 
corporativas. Este Código contiene las prácticas corporativas recomendadas a nivel internacional, lo que hará que a partir de 2001 - fecha de entrada en vigor - el nivel de revelación de información garantizará la transparencia en cuanto a las acciones empresariales más importantes.

3. Falta de provisión de derechos especiales para minorías para defenderse de abusos.- En México, éstas no reciben ningún apoyo por parte de la ley que les ayude a impugnar a los accionistas que detentan el control. No se requiere una proporción mínima de directores externos en la composición del Consejo. Falta un soporte legal para proteger a las minorías que sufren de expropiación. Sólo accionistas con 33\% o más de los votos pueden denunciar al comisario por negligencia u omisión. No existen mecanismos de salida en caso de no estar de acuerdo con ciertas decisiones.

4. Posibilidad de desviarse de la regla un voto por acción. A pesar de que estas estructuras eran prohibidas hasta 1989, fueron entonces permitidas con el fin de incentivar la inversión en acciones por parte de extranjeros. La regulación fue establecida de tal forma que el capital sin derecho a voto en manos de extranjeros no sería considerado como inversión extranjera para fines regulatorios. Sin embargo, la creación de estructuras accionarias duales aumenta potencialmente los incentivos de abuso, ya que permite a los accionistas mayoritarios detentar el control con una menor cantidad de recursos invertidos en la empresa. Con este fin se permitieron los Certificados de Participación Ordinaria (CPOs), los American Depositary Receipts (ADRs) y los Fondos Neutrales. Además, en 1990 se permitió emitir acciones diferentes a las citadas, con derecho a voto limitado o nulo.

En conclusión cuando el accionista mayoritario o una coalición mantiene mayoría absoluta de votos -el caso más común en México- estos accionistas podrán controlar:

- Las decisiones de las reuniones de la Asamblea ordinaria

- Los temas a discutirse en ésta

- La composición del Consejo de Administración

- Las retribuciones a los miembros del Consejo de Administración

- La aprobación de gastos corporativos

- La política de dividendos 
De acuerdo a la evidencia que presenta Babatz (1997) en general en las empresas más grandes en México el Presidente del Consejo también es el director de la empresa o el accionista mayoritario. De manera que es muy fácil para el director expropiar a las minorías.

El problema de conflicto de intereses resulta aun más grave al considerar que es posible mantener el control a un costo "muy bajo", ya que la regulación permite el desvío de un voto por acción y, por ende, no se necesita mantener la mayoría del capital para tener el control $^{15}$.

\section{Conclusiones}

Partiendo de la hipótesis de que la labor de intermediación financiera es crucial para el crecimiento económico, en este trabajo se buscaron algunas medidas concretas que pueden ser instrumentadas para incentivar el desarrollo y eficiencia en los mercados financieros y en última instancia elevar el crecimiento económico. Con este propósito se estudió la importancia de los derechos de propiedad en el desarrollo del mercado crediticio y el de valores.

Al analizar la importancia de la protección a accionistas minoritarios y a acreedores garantizados se encontró que ésta contribuye significativamente al desarrollo de los mercados financieros y éstos últimos a su vez al crecimiento económico del país. En particular, se encontró que un incremento en la capitalización del mercado de valores de $50 \%$ del PIB, el cual se alcanzaría de acuerdo al modelo al incluir las regulaciones propuestas, podría elevar la tasa de crecimiento anual de largo plazo hasta en un punto porcentual. Por el lado del crédito bancario, un aumento de éste en $25 \%$ del PIB, el cual se alcanzaría al incluir las regulaciones propuestas, podría aumentar la tasa de crecimiento anual de largo plazo hasta en 1.5 puntos porcentuales Es importante enfatizar que estos efectos son de largo plazo y que es de esperarse que tarden años en verse materializados.

\footnotetext{
${ }^{15}$ Babatz (1997) encuentra que en México se ha hecho uso de este recurso para mantener el control con menor capital.
} 
Las medidas que resultan más importantes para promover el desarrollo del mercado crediticio son la prelación de los acreedores garantizados en el proceso de disposición de activos en la quiebra de una empresa y la de obligar a la salida del administrador al solicitarse la reorganización de la empresa.

Un aspecto negativo de las medidas que protegen a los acreedores garantizados podría surgir si se orilla frecuentemente a la quiebra a empresas para las que sería óptimo proceder a una reorganización. De ser este el caso estas medidas afectarían negativamente el desarrollo del mercado accionario. Por este motivo se controló por este aspecto al analizar los determinantes de este mercado. Los resultados indican que la protección a los acreedores garantizados tiene incluso un efecto positivo sobre el desarrollo del mercado de valores.

El análisis de los determinantes del desarrollo del mercado crediticio podría enriquecerse al incluir otros aspectos que influyen en el acceso de las empresas al financiamiento externo y aquéllos también pueden ser promovidos por el gobierno, tales como los burós de crédito

En cuanto a la protección de accionistas minoritarios se encuentra que las medidas que tienen mayor impacto son la restricción de un voto por acción, el no permitir que se bloqueen las acciones durante las reuniones de consejo y el contar con mecanismos legales para proteger o defender a los accionistas minoritarios ante expropiación.

Al adoptar especificaciones más generales que permitan un efecto diferente de las variables de interés para países con un buen cumplimiento de la legalidad y para el resto, los resultados se mantienen para el caso de los derechos de los acreedores, pero no para el caso de los derechos de los accionistas minoritarios. Se encuentra que el efecto es significativo y robusto sólo para la restricción de un voto por acción y para los estándares contables. Con base en esto se obtiene que en México el aumento en la capitalización de mercado estaría en un intervalo de $24 \%$ a $32 \%$ del PIB. Con lo anterior, se podría alcanzar un aumento en la tasa de crecimiento económico de largo plazo en un intervalo de 0.4 y 0.6 puntos porcentuales.

Es importante enfatizar que estos resultados deben tomarse con cautela ya que como se mencionó en el documento las instituciones legales juegan un papel fundamental en este ámbito y que posiblemente ello no se capta en su totalidad en las estimaciones realizadas en 
este trabajo. Además hay que mencionar que los cambios regulatorios aquí revisados no son el único camino para mejorar el gobierno corporativo de las empresas emisoras. Para garantizar el mayor éxito es importante utilizar otras medidas complementarias y adicionales a las que pueda hacer uso la autoridad competente.

Contrario a lo esperado se encontró que a pesar de su participación en los mercados financieros internacionales también las empresas grandes se ven afectadas por el marco regulatorio en cuanto a la protección de derechos en su país. Esto se aprecia tanto en sus niveles de endeudamiento como en sus niveles de emisión de capital.

De acuerdo a lo encontrado con respecto a la importancia de la protección de derechos, el efecto positivo de la apertura financiera se podría ver sumamente limitado cuando no se cuenta con un marco regulatorio adecuado y no se incorporan medidas de apertura en el ámbito de resolución de conflictos legales. Este punto requiere de mayor análisis, así como sus implicaciones relativas al impacto del desarrollo de los mercados financieros sobre el crecimiento económico. Sin embargo, en este trabajo se realizaron algunas estimaciones que indican que los tratados y acuerdos internacionales que permiten resolución de conflictos fuera de los tribunales nacionales han tenido un impacto positivo en los flujos de IED a México. El efecto encontrado va de 17\% tomando todos los tratados en su conjunto a $50 \%$ para Canadá y a $68 \%$ para los E.U.A. 


\section{Anexo}

División Mundial por Á rea Geográfica

\begin{tabular}{|c|c|c|c|c|}
\hline América Latina & Asia & D esarrollados & Medio 0 riente & África \\
\hline A rgentina & Bangladesh $^{1}$ & Alemania & Egipto $^{12}$ & Costa de Marfíl ${ }^{1}$ \\
\hline Brasil & Corea $^{6}$ & A ustralia $^{9}$ & Israel & Kenia $^{14}$ \\
\hline Chile & Filipinas & A ustria & Jordania $^{13}$ & Marruecos $^{1}$ \\
\hline Colombia $^{2}$ & $\mathrm{H}$ ong Kong ${ }^{7}$ & Belgica & Pakistan $^{9}$ & Nigeria $^{12}$ \\
\hline Ecuador $^{3}$ & India & Canada & Turquía & Sudáfrica $^{15}$ \\
\hline Jamaica $^{1}$ & Indonesia & Dinamarca & & Zimbawe $^{12}$ \\
\hline México & Malasia & España & & \\
\hline Perú ${ }^{4}$ & Singapur & Estados U nidos & & \\
\hline U ruguay $^{5}$ & Sri Lanka ${ }^{8}$ & Francia & & \\
\hline \multirow[t]{13}{*}{ Venezuela $^{2}$} & T ailandia & Finlandia & & \\
\hline & Taiwan $^{7}$ & Grecia & & \\
\hline & & Holanda & & \\
\hline & & Irlanda ${ }^{10}$ & & \\
\hline & & Italia & & \\
\hline & & Japón & & \\
\hline & & Luxemburgo $^{1}$ & & \\
\hline & & Noruega & & \\
\hline & & Nueva Zelandia & & \\
\hline & & Portugal & & \\
\hline & & Reino Unido & & \\
\hline & & Suecia & & \\
\hline & & Suiza ${ }^{11}$ & & \\
\hline
\end{tabular}

${ }^{1}$ No tienen valores para las variables D ebtgnp, External, D omestic, Ipospop, D ebtcash, D ebtsales, Mcapcash y Mcapsales

${ }^{2} \mathrm{~N}$ o tienen valores para las variables D ebtcash, D ebtsales, Mcapcash y Mcapsales

${ }^{3}$ No tienen valores para las variables Bpy, Mcap, Tvt, D ebtgnp, External, D ebtcash, D ebtsales, Mcapcash y Mcapsales

${ }^{4} \mathrm{~N}$ o tienen valores para las variables Mcap, D ebtcash, D ebtsales, Mcapcash y Mcapsales

${ }^{5} \mathrm{~N}$ o tienen valores para las variables Bpy, Mcap, Tvt, External, D ebtcash, D ebtsales, Mcapcash y Mcapsales

${ }^{6} \mathrm{~N}$ o tienen valores para las variables D ebtcash y Mcapcash

${ }^{7} \mathrm{~N}$ o tienen valores para la variable D ebtgnp

${ }^{8} \mathrm{~N}$ o tienen valores para las variables Bpy, Mcap, Tvt, D ebtcash, D ebtsales, Mcapcash y Mcapsales

${ }^{9} \mathrm{~N}$ o tienen valores para la variable Ipospop

${ }^{10} \mathrm{~N}$ o tienen valores para las variables Bpy, Mcap y Tvt

${ }^{11} \mathrm{~N}$ o tienen valores para las variables Mcap, Tvt, D ebtgnp e Ipospop

${ }^{12} \mathrm{~N}$ o tienen valores para las variables D ebtgnp, Ipospop, D ebtcash, D ebtsales, Mcapcash y Mcapsales

${ }^{13} \mathrm{~N}$ o tienen valores para las variables External, Ipospop, D ebtcash, D ebtsales, Mcapcash y Mcapsales

${ }^{14} \mathrm{~N}$ o tienen valores para las variables Bpy, Mcap, Tvt, D ebtgnp, External, Ipospop, D ebtcash, D ebtsales, Mcapcash y Mcapsales

${ }^{15} \mathrm{~N}$ o tienen valores para las variables Mcap y T vt 


\section{Bibliografía}

Babatz, G, 1997, "Problemas de Agencia, Estructura de Propiedad y Estructura de Control Bajo Prácticas Laxas de Gobierno Corporativo: El Caso de México”, Universidad de Harvard, mimeo.

Barclay, M. y C. Holderness, 1998, "Private Benefits from Control of Public Corporations", Journal of Financial Economics, 25, 371-395.

Banco Interamericano de Desarrollo, 1999, Reporte para México.

Berkowitz, J. y M. White, 1999, “Bankruptcy and Small Firms`Access to Credit”, mimeo.

Bhattacharya, U., H. Daouk, B. Jorgenson y C.-H. Kehr, 2000, "When an Event is not an Event: The Curious Case of an Emerging Market", Journal of Finance Economics 55, 69101.

Claessens, S. S. Djankov, Fan y L. Lang, 1999, "Expropriation of Minority Shareholders: Evidence from East Asia" mimeo.

Dyck, A., 2000, "Ownership Structure, Legal Protections and Corporate Governance" Annual Bank Conference on Development Economics, World Bank.

Gibson, M, 1999, “Is Corporate Governance Ineffective in Emerging Markets?", Federal Reserve Board, Finance and Economics Discussion Series, 1999-63.

Gupta, S., H. Davoodi y R. Alonso-Terme, 1998, "Does Corruption Affect Income Inequality and Poverty?”, IMF Woeking Paper 98/76, mayo.

King, R. y R. Levine, 1993, "Finance and Growth: Schumpeter Might Be Right", Quarterly Journal of Economics, 108, 717-738.

Knack, S. Y P. Keefer, 1996, "Institutions and Economic Performance: Cross-Country Tests Using Alternative Institutions Measures," Economics and Politics, Vol. 7 (noviembre), No. 3, 207-27.

La Porta, R., F. López de Silanes, A. Shleifer, y R. Vishny, 1999a, "Investor Protection and Corporate Governance".

517. 1999b, “Corporate Ownership around the World", Journal of Finance, 54, 471-

1999c, "The Quality of Government", Journal of Law, Economics, and Organization, 15, 222-279. 1998, "Law and Finance", Journal of Political Economy, 106, 1113-1155. 
$1131-1150$.

1997, "Legal Determinants of External Finance", Journal of Finance 52,

Levine, R., 1998, “The Legal Environment, Banks, and Long-Run Economic Growth", Journal of Money, Credit and Banking, Vol. 30, No. 3, 597-620.

Levine, R., N. Loayza y T. Beck, 1998, "Financial Intermediation and Growth: Causality and Causes", mimeo.

Levine, R. y S. Zervos, 1998, "Stock Markets, Banks, and Economic Growth", American Economic Review, 88, 537-557.

Malitz, I., 1989, "A Re-Examination of the Wealth Expropriaton Hypothesis: The Case of Captive Finance Subsidiaries”, Journal of Finance, 46, 1039-1047.

Mauro, P., 1995, “Corruption and Growth”, The Quarterly Journal of Economics, agosto.

Pulvino, T., 1999, "Effects of Bankruptcy Court Protection on Asset Sales", Journal of Financial Economics 52, 151-186.

Rajan, R. y L. Zingales, 1996, "Financial Dependence and Growth", Working Paper 5758, National Bureau of Economics.

Schumpeter, J., 1911, The Theory of Economic Development, Cambridge, MA: Harvard University Press.

Shleifer, A. y R. Vishny, 1997, “A Survey of Corporate Governance”, Journal of Finance, $52,737-783$.

Slovin, M. y M. Sushka, 1997, "The Implications of Equity Issuance Decisions within a Parent-Subsidiary Governance Structures", Journal of Finance, 52, 841-857.

Thorburn, K. S., 1999, "Bankruptcy Auctions: Costs, Debt Recovery, and Firm Survival”, Darmouth College, mimeo.

, 1998, "Bancruptcy Auctions: CEO Turnover, Compensation Changes and Firm Performance", Darmouth College, mimeo.

White, M., 1996, The Costs of Corporate Bankruptcy: A U.S.-European comparison, en Corporate Bankruptcy: Economic and Legal Perspectives, Editado por J. S. Bhandari y L. A. Weiss, Cambridge University Press. 